Revistade
Economila
Contemporâned

\title{
TRABALHO INFANTIL NO BRASIL URBANO: QUAL A IMPORTÂNCIA DA ESTRUTURA FAMILIAR?
}

\author{
Shirley Pereira de Mesquita ${ }^{a}$ \\ Hilton Martins de Brito Ramalho ${ }^{b}$ \\ aDepartamento de Economia da Universidade Federal da Paraíba (UFPB). \\ bPrograma de Pós-Graduação em Economia da UFPB. \\ Artigo recebido em 13/09/2013 e aceito em 18/06/2015.
}

RESUMO: O artigo investiga a importância da estrutura familiar na determinação do trabalho infantil no meio urbano do Brasil. Para tanto, foram utilizados dados do Censo Demográfico de 2010 e um modelo probit para a decisão de oferta de trabalho infantil. Os resultados mostraram que meninos, com 14 anos de idade e cujo pai (mãe) não tem instrução, são mais propensos à entrada precoce no mercado de trabalho. Também foram achadas evidências de que crianças de lares com mãe solteira têm maior chance de trabalharem quando comparadas com crianças oriundas de domicílios biparentais sob responsabilidade do pai e com padrão de renda similar. A condição desfavorável das crianças em lares monoparentais apenas é eliminada quando a renda domiciliar alcança um patamar elevado o bastante para reduzir fortemente a probabilidade de trabalho infantil. A diferença de probabilidade de trabalho infantil entre famílias monoparentais e biparentais é explicada principalmente por diferenças de comportamento entre os tipos de família.

PALAVRAS-CHAVE: trabalho infantil; estrutura familiar; Brasil urbano.

CLASSIFICAÇÃO JEL: J22; C35; D10. 


\title{
CHILD LABOR IN URBAN BRAZIL: WHAT IS THE ROLE OF THE FAMILY STRUCTURE?
}

\begin{abstract}
The aim of this paper is to investigate the role of single parents on child labor in urban Brazil. We use data provided by Brazilian Demographic Census of 2010 and a probit model to account the choice for child labor. The results show that boys, age 14 whose parents have low level of education are more likely to work. We also find that children living with single mother have more likelihood to work than children who live in two-parent family, both at same level of income. The unfavorable condition of children in single-parent households only vanishes when the household income reaches a threshold level that strongly decreases the child labor's propensity. The difference in child labor between the two groups of families is mainly due to their unobserved behaviors.
\end{abstract}

KEY WORDS: child labor; single parents; urban Brazil. 


\section{INTRODUÇÃO}

O trabalho infantil produz consequências negativas sobre o desenvolvimento físico, emocional, social e profissional das crianças (Minayo-Gomes e Meirelles, 1997; Emerson e Portela Souza, 2005; Beegle et al., 2007). Dentre tais efeitos, pode-se destacar, por um lado, a entrada tardia na escola, a evasão escolar, os baixos desempenho e frequência escolares e danos à saúde física e mental $^{1}$ (Patrinos e Psacharopoulos, 1997; Cavalieri, 2002; Heady, 2003), e, por outro, a redução verificada nos rendimentos do trabalho durante a vida adulta (Ilahi, Orazem e Sedlacek, 2000; Kassouf, 2005; Emerson e Portela Souza, 2005). Não obstante, segundo informações do estudo do Fundo das Nações Unidas para a Infância (UNICEF), em 2010, cerca de 150 milhões de crianças entre 5 e 16 anos estavam trabalhando no mundo, sendo a maior incidência em países subdesenvolvidos (UNICEF, 2011).

No Brasil, a inserção de crianças no mercado trabalho tem sido foco de discussões políticas nos anos recentes, principalmente em razão do compromisso firmado pelo Ministério do Trabalho e Emprego (MTE) com a Organização Internacional do Trabalho (OIT), que foi reafirmado em 2014. O MTE se comprometeu a eliminar as piores de formas de trabalho infantil até 2016 e alcançar a erradicação total até 2020. Apesar da intensificação das medidas de combate ao trabalho infantil a partir de 1992, através da integração do país ao Programa Internacional para a Erradicação do Trabalho Infantil $(\text { IPEC) })^{2}$ e do quadro de redução apresentado nos últimos 10 anos, os dados do Censo Demográfico de 2010 do Instituto Brasileiro de Geografia e Estatística (IBGE) apontam que cerca de 1 milhão de crianças entre 10 e $14^{3}$ anos ainda trabalham, sobretudo, nas piores formas de trabalho infantil estabelecidas internacionalmente, a exemplo de atividades informais no meio urbano, na agricultura familiar, em serviços domésticos e atividades ilícitas (Franklin et al., 2001). Ademais, ao se cotejar os dados dos Censos Demográficos de 2000 e 2010, percebe-se um leve aumento na taxa de trabalho infantil, 1,6\%, na faixa etária de 10 a 13 anos. Já quanto à distribuição regional, o trabalho infantil é mais concentrado nas regiões Norte (9\%) e Nordeste (8\%); fato que pode reforçar as desigualdades regionais e as condições econômicas das crianças trabalhadoras na vida adulta ${ }^{4}$.

1 Tais consequências caracterizam o trabalho infantil como uma violação aos direitos humanos.

2 A iniciativa trata-se de um programa mundial de cooperação técnica contra o trabalho infantil, cujo objetivo é estimular, orientar e apoiar iniciativas nacionais na formulação de políticas e ações diretas que coíbam a exploração da infância.

3 Esse número equivale a, aproximadamente, 3\% do total de crianças na faixa etária de 10 a 14 anos de idade. No Brasil, $94 \%$ das crianças trabalhadoras se acham nessa faixa etária.

4 A literatura aponta que o trabalho infantil tem efeitos negativos sobre a trajetória de crescimento econômico de uma região, sobretudo devido à redução no acúmulo de capital humano (Basu, 1999; Galli, 2001). 
A literatura especializada é controversa quanto aos determinantes do trabalho infantil, dado estes que variam entre países e regiões estudadas. Apesar disso, a condição de pobreza é comumente aceita como um fator relevante para o referido fenômeno. As características da criança, do responsável pela família, do mercado de trabalho, a localização e a estrutura familiar também são bastante correlacionadas com o trabalho infantil (Kassouf, 2005; Kassouf, 2007; Ferreira Batista e Cacciamali, 2007; Aquino et al., 2010).

No tocante às características da estrutura familiar, as variáveis explicativas mais comuns nos estudos empíricos são o tamanho da família, número de irmãos por faixa etária, gênero da pessoa responsável pelo domicílio e presença de cônjuge no domicílio (Barros, Mendonça e Velazco, 1994; Grootaert e Patrinos, 2002; Emerson e Portela Souza, 2007; Kassouf, 2010; Aquino et al., 2010). De forma geral, os estudos citados sugerem que o tamanho da família e o número de irmãos mais novos estimulam o trabalho infantil, enquanto a presença de cônjuge e/ou de chefe domiciliar do sexo masculino reduz. No Brasil, algumas pesquisas avaliam a interação entre a presença do cônjuge e o gênero do responsável pelo domicílio, ao classificarem famílias em monoparentais ${ }^{5}$ e biparentais sob responsabilidade da mãe ou do pai (Cavalieri, 2002; Ferreira Batista e Cacciamali, 2007). Em linhas gerais, os resultados desses estudos indicam que a diferença de gênero entre chefes, em conjunto com a presença de apenas um dos responsáveis na família, afetam a escolha dos pais quanto à inserção dos filhos no mercado de trabalho, isto é, a incidência de trabalho infantil parece ser maior em famílias sob responsabilidade de mulheres que não convivem com cônjuge.

Vitale (2002) argumenta que crianças em famílias monoparentais chefiadas por mulheres têm maior vulnerabilidade psicológica e socioeconômica. Ademais, pesquisas na área da sociologia sugerem que crianças inseridas em lares com apenas um responsável, pai ou mãe, estão mais propensas a problemas de rendimento escolar, trabalho infantil, delinquência, suicídio e violência, além de viverem em pior situação socioeconômica em relação às crianças criadas por ambos os pais (Amato, 1993; Rushton e McLanahan, 2002). No Brasil, quando se consideram domicílios onde o(a) responsável tem ao menos um filho com até 14 anos de idade, é possível observar que o percentual de famílias monoparentais aumentou de 13,5\% para 15,8\% entre 2000 e 2010, conforme dados dos Censos Demográficos do IBGE $^{6}$. Esse crescimento pode estar relacionado às mudanças demográficas e sociais ocorridas nas últimas décadas no

\footnotetext{
5 A família monoparental é formada pelo responsável (pai ou mãe) e filhos, sem a presença de cônjuge. No Brasil, esse tipo de estrutura só foi reconhecido como entidade familiar na Constituição Federal de 1988 (artigo 226, parágrafo $4^{\circ}$ ). Já a família biparental é composta pelo responsável (pai ou mãe), o cônjuge e os filhos.

6 Cabe ainda destacar a forte concentração das referidas famílias nas áreas urbanas, isto é, 82,3\% de famílias biparentais e $90,6 \%$ de famílias monoparentais, conforme dados do Censo de 2010.
} 
país, principalmente em razão da redução da burocracia jurídica envolvida nos processos de divórcio e ao crescimento da participação da mulher no mercado de trabalho (Hoffmann e Leone, 2004). Ademais, os dados do Censo Demográfico de 2010 indicam dois padrões típicos de famílias no Brasil urbano: a família biparental sob responsabilidade masculina $(61,2 \%)$ e a família monoparental chefiada por mulher $(15,6 \%)$.

Dada a discussão anterior, cabe o seguinte questionamento: qual o efeito da estrutura familiar monoparental na decisão de oferta de mão de obra das crianças? Ou seja, em que medida o fato de a criança conviver em domicílio com apenas um dos pais, especialmente com a mãe, pode favorecer o trabalho infantil em relação à convivência em um lar biparental com atributos médios semelhantes? Investigar tal questão, pouco explorada no Brasil, pode fornecer novos parâmetros para políticas de combate ao trabalho infantil, haja vista a possibilidade de o referido fenômeno manifestar-se de forma diferenciada por tipo de família. Destarte, o presente estudo pretende contribuir para a literatura ao explorar com propriedade a relação entre trabalho infantil e estrutura familiar, condicionada a um conjunto de características individuais, de mercado de trabalho e de localização regional.

Além desta introdução, este artigo está organizado da seguinte forma: a segunda seção apresenta uma breve revisão da literatura, reportando as principais evidências que relacionam o trabalho infantil à estrutura familiar. A terceira seção traça um rápido panorama do trabalho infantil no Brasil durante a última década. Na quarta seção, apresentam-se a estratégia empírica do presente estudo, a base de dados e a seleção da amostra. A quinta seção reporta os achados empíricos sobre os principais determinantes do trabalho infantil no Brasil e sua relação com a estrutura familiar. Por fim, a sexta é reservada às considerações finais.

\section{TRABALHO INFANTIL E CARACTERÍSTICAS DA FAMÍLIA}

A literatura sobre trabalho infantil sugere que a decisão dos pais, no tocante à alocação do tempo das crianças entre trabalho, escola e lazer, faz parte de uma estratégia para reduzir a pobreza (Grootaert e Kanbur, 1995; Ray, 2000). O modelo de Basu e Van (1998), por exemplo, mostra que os pais são altruístas e preferem investir no capital humano dos filhos, isto é, enviá-los à escola. Essa hipótese é conhecida como axioma do luxo ${ }^{7}$. Por outro lado, eles inserem seus filhos no mercado de trabalho apenas se

\footnotetext{
No modelo teórico de Basu e Van (1998), as famílias consideram o tempo de lazer e de estudo das crianças como um bem de luxo. Isso implica que os pais substituem o trabalho infantil por lazer e estudo à medida que a renda familiar aumenta.
} 
isso for necessário para sua própria sobrevivência, o chamado axioma da renda. Alguns estudos empíricos corroboram essa teoria e mostram que o aumento da renda familiar reduz (aumenta) a probabilidade de a criança trabalhar (estudar) (Kassouf, 1999; Edmonds, 2007).

Há alguns estudos que tratam da relação de gênero entre pais e filhos. $O$ trabalho de Thomas (1994), por exemplo, aponta que a educação dos pais é um fator importante na determinação da alocação de recursos domésticos, em especial, no tempo de trabalho dos filhos. Já Degraff, Levison e Robison (2009) examinam a relação entre os fatores determinantes do trabalho de mães e filhos no Brasil. Seus resultados sugerem que as mães e as crianças respondem de forma semelhante a incentivos do mercado de trabalho.

Por outro lado, outros estudos empíricos argumentam que a pobreza não é o principal fator explicativo do trabalho infantil, e sugerem a incorporação de características das crianças e dos pais, de localização, do mercado de trabalho e de estrutura e composição da família, entre outras (Edmonds e Turk, 2002; Bhalotra e Heady, 2003). Nesse contexto, a estrutura familiar parece ter um papel central na determinação do trabalho infantil, dado que a escolha de alocação do tempo da criança entre trabalho, estudo e lazer é feita pelos pais (Basu e Van, 1998; Baland e Robinson, 2000).

Os efeitos do tamanho da família e da faixa etária de seus membros na escolha de trabalho infantil são reportados de forma estatisticamente significante em alguns estudos empíricos. Hill e Duncan (1987), por exemplo, sugerem que o número de irmãos aumenta a probabilidade de trabalho infantil nos Estados Unidos. Barros, Mendonça e Velazco (1994), por sua vez, mostram que quanto maior o número de irmãos e/ou irmãs menores de 10 anos, maior a probabilidade de a criança trabalhar no Brasil urbano; fato justificado pela importância da renda obtida com o trabalho das crianças maiores de 10 anos. Ademais, também é possível encontrar resultados semelhantes nos estudos de Patrinos e Psacharopoulos (1997) para o Peru; Grootaert e Patrinos (2002), para Colômbia, Bolívia, Filipinas e Costa do Marfim; Emerson e Portela Souza (2008), Kassouf (1999), Kassouf (2005), Kassouf (2010) e Cacciamali, Ferreira Batista e Tatei (2011), para o Brasil. Em linhas gerais, esses estudos sugerem que famílias grandes tendem a registrar menor renda per capita e maior proporção de dependentes, fatores que aumentam a vulnerabilidade e a necessidade da renda gerada pelas crianças.

Vale também ressaltar que uma parte da literatura especializada aborda de forma mais detalhada o efeito da estrutura familiar sobre a decisão de trabalho infantil sob as óticas teórica e empírica. Manski et al. (1992), Moehling (2004) e Biblarz e Gottainer (2000), por exemplo, definem como família de referência a categoria biparental chefiada pelo pai e analisam os efeitos sobre o bem-estar da criança em comparação com famílias monoparentais chefiadas pela mãe, em alguns casos, diferenciando o motivo 
da ruptura conjugal, isto é, observando as diferenças entre famílias em que a mãe é viúva em relação àquelas em que são divorciadas. Manski et al. (1992) destacam que a criança que cresce em uma família monoparental, sobretudo chefiada pela mãe, tem em média pior rendimento escolar e maior taxa de evasão, é mais propensa à entrada precoce no mercado de trabalho, tem maior chance de ter filhos fora do casamento, dificuldades no mercado de trabalho na fase adulta e, geralmente, níveis mais baixos de bem-estar psicológico (felicidade) em relação àquela que vive com os dois pais (McLanahan e Bumpass, 1988; Manski et al.,1992; Degraff e Bilsborrow, 1993; McLanahan e Sandefur, 1994; Biblarz e Gottainer, 2000; Moehling, 2004). No entanto, ainda há uma lacuna no tocante à exploração dos possíveis canais de transmissão dos efeitos reportados, em especial, sobre o trabalho infantil.

Um dos canais que relacionam a estrutura familiar monoparental e o trabalho infantil é a condição de pobreza de algumas famílias nessa categoria, principalmente devido às diferenças salariais provocadas pela condição de gênero no mercado de trabalho e ao nível de educação - características que podem reduzir a renda domiciliar e, provavelmente, aumentar a chance de trabalho infantil ${ }^{8}$ (Bhalotra e Heady, 2003; Carloto, 2005). Fialho (2004) argumenta que as mães podem enfrentar dificuldades ao tentar exercer funções domésticas, trabalhar fora de casa, chefiar a família e cuidar da educação e socialização dos filhos, simultaneamente. Esse cenário pode induzi-las a transferir parte da responsabilidade familiar para os filhos, como uma estratégia de suprir a ausência do cônjuge. Nesse contexto, as crianças podem ser inseridas precocemente no mercado de trabalho e/ou podem ter intensificadas suas horas em afazeres domésticos, a fim de dividir com a mãe as despesas da família (Sorj e Fontes, 2008).

Alguns estudos empíricos para o Brasil reportam evidências empíricas sobre maior propensão ao trabalho infantil em famílias monoparentais chefiadas pela mãe. Cacciamali, Ferreira Batista e Tatei (2008) mostram que o sexo do chefe da família é importante para a incidência do trabalho infantil, em particular, quando se trata de uma mulher sem cônjuge, isto é, suas evidências mostram que a probabilidade de a criança trabalhar aumenta nesse caso. Já Barros, Mendonça e Velazco (1994) sugerem que a renda não é a única causa do trabalho infantil no Brasil, mas ser menino, ter cor parda e pertencer a famílias numerosas e chefiadas por mulheres são características que afetam diretamente o trabalho infantil. Ademais, também pode ser citado o estudo de Duryea et al. (2005) para o Brasil, Nicarágua e Peru, que destaca a maior probabilidade de trabalho infantil em domicílios chefiados por mulheres.

\footnotetext{
8 Isso não significa que famílias monoparentais chefiadas pela mãe são mais pobres que famílias biparentais. Outros fatores como escolaridade e ocupação da mãe devem ser considerados.
} 


\section{TRABALHO INFANTIL NO BRASIL: FATOS OBSERVADOS}

A OIT fixou como idade mínima recomendada para o trabalho, em geral, os 16 anos$^{9}$. No caso dos países-membros considerados muito pobres, a OIT admite que seja fixada, inicialmente, uma idade mínima de 14 anos. No caso do Brasil, é proibido o trabalho noturno, perigoso ou insalubre aos menores de 18 anos, assim como de qualquer forma de trabalho para os menores de 16 anos, exceto como aprendiz ${ }^{10}$ apenas a partir dos 14 anos. Apesar das proibições impostas pelas leis trabalhistas e das políticas de combate ao trabalho infantil, o Brasil ainda tem um número considerável de crianças inseridas no mercado de trabalho, conforme será discutido a seguir.

A Tabela 1 apresenta a distribuição do trabalho infantil no Brasil por setor censitário e segundo grandes regiões entre os anos de 2000 e 2010. É possível observar que, no meio urbano, há maior concentração de crianças trabalhadoras na região Sudeste, seguida pela região Nordeste. Embora a quantidade de crianças trabalhadoras na zona urbana tenha reduzido em todas as regiões, a distribuição ficou mais concentrada no Sudeste, Sul e Centro-Oeste durante o período em análise. Já na zona rural, a região Nordeste registra o maior percentual de crianças trabalhadoras, seguida pelas regiões Norte e Sul.

Tabela 1 - Brasil: distribuição de crianças trabalhadoras (10 a 14 anos de idade) segundo a região de residência e por setor censitário, 2000 e 2010

\begin{tabular}{lccrr}
\hline \multirow{2}{*}{ Região } & \multicolumn{2}{c}{$\mathbf{2 0 0 0}$} & \multicolumn{2}{c}{$\mathbf{2 0 1 0}$} \\
\cline { 2 - 5 } & Zona Urbana & Zona Rural & Zona Urbana & Zona Rural \\
\hline Norte & $37.212(9,4 \%)$ & $11.760(10,3 \%)$ & $29.356(9,1 \%)$ & $27.223(19,6 \%)$ \\
Nordeste & $116.328(29,2 \%)$ & $52.193(45,8 \%)$ & $82.934(25,6 \%)$ & $59.218(42,5 \%)$ \\
Sudeste & $148.735(37,4 \%)$ & $30.428(26,7 \%)$ & $125.061(38,6 \%)$ & $20.902(15,0 \%)$ \\
Sul & $53.625(13,5 \%)$ & $14.802(13,0 \%)$ & $51.104(15,8 \%)$ & $26.664(19,2 \%)$ \\
Centro-Oeste & $41.824(10,5 \%)$ & $4.657(4,1 \%)$ & $35.560(11,0 \%)$ & $5.182(3,7 \%)$ \\
Total & $397.724(100 \%)$ & $113.840(100 \%)$ & $324.015(100 \%)$ & $139.190(100 \%)$ \\
\hline
\end{tabular}

Notas: Resultados expandidos para o universo. Apenas crianças que registraram trabalho remunerado. Fonte: Elaboração própria com base em microdados dos Censos Demográficos de 2000 e 2010.

O total de crianças trabalhadoras mais que dobrou na zona rural das regiões Norte e Sul do Brasil entre 2000 e 2010. Esse fato pode estar relacionado à dificuldade de fiscalização no meio rural, dado que a maior parte das crianças exerce atividades de

9 Ver Convenção no 138 , de 1973, no artigo $2^{\circ}$, itens 3 e 4.

${ }^{10} \mathrm{Na}$ condição de aprendiz, a criança ou adolescente deve ser submetida a uma jornada de no máximo 6 horas diárias, sendo proibido qualquer tipo de prorrogação ou compensação. Apenas nos casos em que o aprendiz já terminou o ensino fundamental o limite aumenta para oito horas diárias, desde que, entre as atividades desenvolvidas, estejam computadas as horas destinadas à aprendizagem teórica. 
subsistência. Somam-se a essa situação a escassez e a precariedade das escolas na zona rural. Em linhas gerais, nota-se que, no Brasil, o quantitativo de crianças inseridas no mercado trabalho tem crescido mais na zona rural em comparação à urbana.

O Gráfico 1 apresenta o percentual de crianças trabalhadoras no Brasil segundo a idade e por setor censitário e gênero a partir dos dados do Censo Demográfico de 2010.

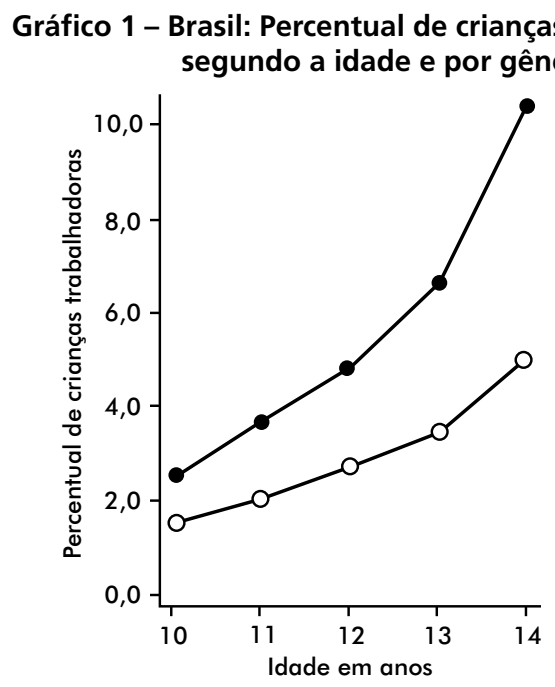

(a) Zona rural
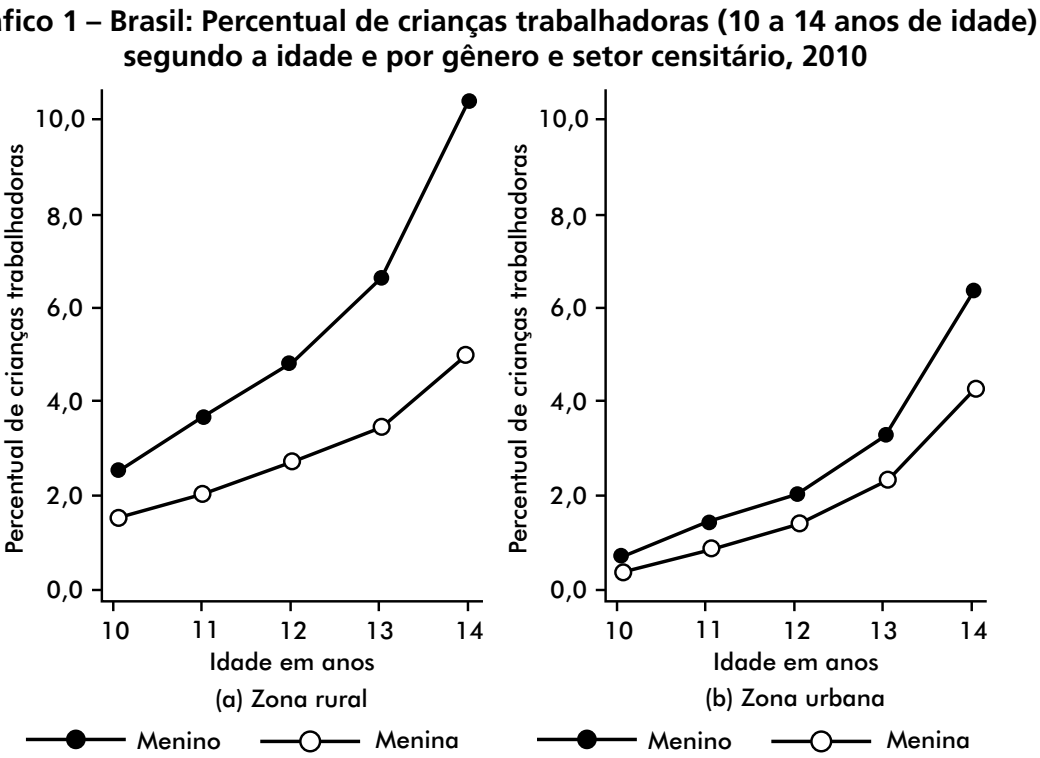

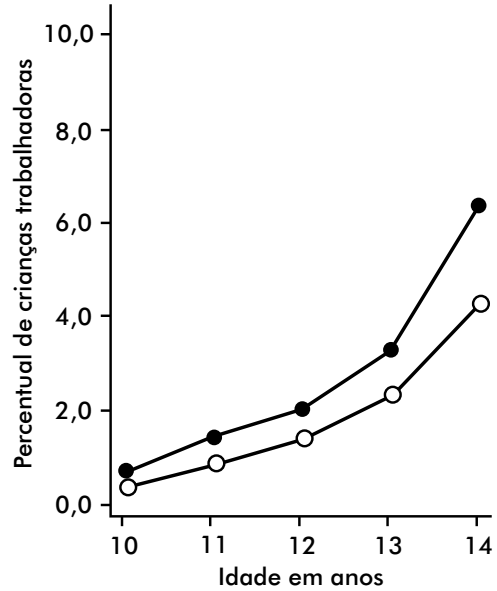

(b) Zona urbana

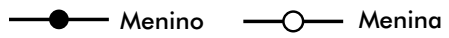

Notas: Resultados expandidos para o universo. Apenas crianças que registraram trabalho remunerado. Fonte: Elaboração própria com base em microdados do Censo Demográfico de 2010.

Conforme pode ser observado, a intensidade do trabalho infantil aumenta consideravelmente com a idade da criança; fato corroborado por outros estudos (Emerson e Portela Souza, 2007; Aquino et al., 2010; Cacciamali, Ferreira Batista e Tatei, 2011). No meio rural brasileiro, o trabalho infantil é mais intenso, a despeito do gênero e da idade da criança. Também é possível constatar que os meninos são mais vulneráveis à inserção precoce no mercado de trabalho. Em geral, para o mercado de trabalho, a força de trabalho dos meninos é mais atrativa, em razão de as atividades executadas se tratarem quase sempre de algo que envolve força física e até riscos à criança. Cabe ressaltar que as meninas estão mais envolvidas em afazeres domésticos, atividades que, culturalmente, não são consideradas pelos pais como trabalho infantil.

O trabalho infantil, além dos efeitos adversos no período corrente, tem uma influência direta na qualidade e na expectativa de vida das crianças na fase adulta, sobretudo devido ao seu efeito sobre a acumulação de capital humano ao longo da vida. 
Ilahi, Orazem e Sedlacek (2000), Kassouf (2005) e Emerson e Portela Souza (2005), em estudos feitos para o Brasil, fornecem evidências de que crianças trabalhadoras alcançam níveis menores de renda na idade adulta, em comparação àquelas que não trabalharam durante a infância. Em particular, o estudo Repórter-Brasil (2012) mostra que a criança que começa a trabalhar antes dos 14 anos tem uma probabilidade muito baixa de conseguir rendimentos superiores a $\mathrm{R} \$ 1.000,00$ por mês ao longo da vida. A maioria daqueles que iniciam a trajetória laboral antes dos nove anos tem baixa probabilidade de receber rendimentos superiores a $\mathrm{R} \$ 500,00$ mensais, em média.

A Tabela 2 mostra que as crianças que trabalham têm menor frequência escolar em relação àquelas que não trabalham, especialmente entre os meninos. Outro fator de destaque é o problema da evasão escolar entre as crianças trabalhadoras, pois o abandono dos estudos, de forma temporária ou permanente, provoca sérias consequências sobre o progresso econômico na fase adulta.

Tabela 2 - Brasil: distribuição de crianças (10 a 14 anos de idade) segundo a frequência escolar e por gênero e trabalho infantil, 2010

\begin{tabular}{lrrrr}
\hline & \multicolumn{2}{c}{ Menino } & \multicolumn{2}{c}{ Menina } \\
\cline { 2 - 5 } & Trabalha & Não trabalha & Trabalha & Não trabalha \\
\hline Frequenta escola pública & 218.697 & 7.062 .455 & 139.823 & 6.923 .551 \\
& $75,6 \%$ & $83,7 \%$ & $80,4 \%$ & $83,8 \%$ \\
Frequenta escola particular & 10.440 & 1.103 .857 & 8.330 & 1.094 .933 \\
& $3,6 \%$ & $13,1 \%$ & $4,8 \%$ & $13,3 \%$ \\
Não frequenta escola, mas já frequentou & 56.507 & 195.961 & 24.410 & 187.059 \\
& $19,5 \%$ & $2,3 \%$ & $14,0 \%$ & $2,3 \%$ \\
Nunca frequentou escola & 3.561 & 75.617 & 1.437 & 60.498 \\
Total & $1,2 \%$ & $0,9 \%$ & $0,8 \%$ & $0,7 \%$ \\
& 289.205 & 8.437 .890 & 174.000 & 8.266 .040 \\
\hline
\end{tabular}

Notas: Resultados expandidos para o universo. Apenas crianças que registraram trabalho remunerado. Fonte: Elaboração própria com base em microdados do Censo Demográfico de 2010.

As crianças brasileiras exercem atividades das mais diversas, sobretudo aquelas consideradas, internacionalmente, as piores formas de trabalho infantil, a exemplo do trabalho doméstico, agricultura familiar, produção familiar dentro do próprio domicílio, comércio informal urbano, e as ilícitas, como prostituição e tráfico de drogas (Franklin et al., 2001). O trabalho de Degraff, Levison e Ferro (2014) aponta que, no Brasil, há uma maior participação das meninas em atividades consideradas de risco e que as crianças envolvidas nesse tipo de trabalho têm, em média, menor chance de frequentar a escola e uma jornada de trabalho mais intensa em relação àquelas envolvidas em outros tipos de ocupação. A Tabela 3 registra a distribuição do trabalho infantil segundo ramos de atividades econômicas e por zona de residência e gênero. 
Tabela 3 - Brasil: distribuição percentual de crianças trabalhadoras (10 a 14 anos de idade) segundo ramos de atividade e por setor censitário e gênero, 2010

\begin{tabular}{lrrrrrr}
\hline \multirow{2}{*}{ Ramo de atividade } & \multicolumn{3}{c}{ Zona urbana } & \multicolumn{3}{c}{ Zona rural } \\
\cline { 2 - 7 } & Menino & Menina & Total & Menino & Menina & Total \\
\hline Agricultura e Pesca & 9,2 & 3,2 & 6,8 & 79,8 & 60,8 & 73,5 \\
Indústria & 23,9 & 12,0 & 19,2 & 7,7 & 9,2 & 8,2 \\
Comércio e Serviços & 49,8 & 35,0 & 43,9 & 6,9 & 7,7 & 7,2 \\
Serviços Sociais & 6,7 & 11,3 & 8,5 & 0,8 & 1,7 & 1,1 \\
Serviços Domésticos & 2,0 & 30,7 & 13,3 & 1,0 & 14,3 & 5,4 \\
Outras Atividades & 8,5 & 7,7 & 8,2 & 3,8 & 6,3 & 4,6 \\
Total & 100 & 100 & 100 & 100 & 100 & 100 \\
\hline
\end{tabular}

Notas: Resultados expandidos para o universo. Apenas crianças com trabalho remunerado.

Fonte: Elaboração própria com base em microdados do Censo Demográfico de 2010.

Os dados da Tabela 3 mostram que, no meio urbano do país, a concentração do trabalho infantil está nos setores de Comércio e Serviços, seguido por Indústria, principalmente entre os meninos. Vale ressaltar que as condições de trabalho no meio urbano brasileiro penalizam mais a saúde das crianças em relação às do meio rural (Nicolella, Kassouf e Barros, 2008). Já na zona rural, o maior percentual de crianças trabalhadoras é achado nas atividades de agricultura e pesca, a despeito do sexo da criança. Outro dado interessante está na atividade de serviços domésticos, o segundo maior entre as meninas nas zonas urbana e rural. Este dado é preocupante, já que essa é uma das atividades que mais provocam danos à saúde física e emocional da criança. Segundo informações do estudo Repórter-Brasil (2012), entre 2007 e 2011 ocorreram cerca de 7,5 mil casos de acidente de trabalho doméstico ou no campo envolvendo crianças registrados no Sistema Único de Saúde (SUS).

No tocante ao combate ao trabalho infantil, destaca-se que a partir de 2002 o Brasil passou a integrar o Programa Internacional para a Erradicação do Trabalho Infantil (IPEC), um dos mais importantes instrumentos de cooperação da OIT com os países membros. A iniciativa trata-se de um programa mundial de cooperação técnica contra o trabalho infantil, cujo objetivo é estimular, orientar e apoiar iniciativas nacionais na formulação de políticas e ações diretas que coíbam a exploração da infância. Já no ano de 1998 foi instituída a Emenda Constitucional de número 20, que alterou a idade mínima de ingresso no mercado de trabalho para 16 anos e proibiu o trabalho para menores de 14 anos, mesmo na condição de aprendiz. No mesmo ano, foi estabelecido o Programa de Erradicação do Trabalho Infantil (PETI), cujo principal objetivo é contribuir para a erradicação de todas as formas de trabalho infantil no país. Segundo Yap, Sedlacek e Orazem (2003), o PETI teve efeito positivo no combate à participação infantil no mercado de trabalho. Seus resultados apontam que as crianças participantes do programa tinham uma maior frequência e melhores resultados escolares e, por outro lado, trabalhavam menos e alocavam menos tempo em trabalhos de risco. 
No ano 2000, o Brasil e mais 161 países ratificaram as Convenções 182 e 138 da OIT, que tratam da proibição das piores formas de trabalho infantil, bem como do combate, coibição e da idade mínima de ingresso no mercado de trabalho. Entre 2000 e 2010, a proporção de crianças trabalhando no Brasil reduziu cerca de 10 p.p. Esse comportamento pode estar relacionado às melhorias econômicas do país na última década, e, de forma indireta, ao conjunto de medidas adotadas pelo Governo Federal, com destaque para o Programa Bolsa Família, que atua na redução da pobreza, um dos principais condicionantes do trabalho infantil. Apesar da redução, é importante destacar que persistem, no país, as piores formas de trabalho infantil definidas pela OIT, que são as mais difíceis de combater, devido à dificuldade de identificação e de fiscalização ${ }^{11}$.

\section{ESTRATÉGIA EMPÍRICA}

\subsection{DETERMINANTES DO TRABALHO INFANTIL}

Este estudo investiga os determinantes do trabalho infantil para crianças de 10 a 14 anos no Brasil urbano, destacando o impacto da estrutura familiar sob essa decisão. Para tanto, faz-se necessário o uso de um instrumental econométrico apropriado.

Considerando as estruturas de famílias mais frequentes no Brasil, isto é, a família monoparental chefiada pela mãe (grupo A) e a família biparental em que o pai é o responsável (grupo B), defina-se $Y_{g}^{*}$ como uma variável latente (contínua e não observada) que mede o ganho de utilidade advindo da escolha de inserção precoce no mercado de trabalho para a família do grupo $g=A, B$. Desse modo, os pais optam por ofertar trabalho infantil se o benefício esperado for positivo $Y_{g}^{*}>0$, e por não ofertar em caso contrário $Y_{g}^{*} \leq 0$. Esse benefício esperado está condicionado a um conjunto de características da criança, dos pais e do mercado de trabalho local, sintetizadas na matriz $X_{g}$ e conforme a equação abaixo ${ }^{12}$.

$$
Y_{g}^{*}=X_{g} \beta_{g}+\varepsilon_{g}
$$

Em (1), $\beta g$ é o vetor de parâmetros do modelo (inclusive intercepto) e $\varepsilon_{g}$ é um termo de erro randômico com média zero e variância constante.

\footnotetext{
${ }^{11}$ No Brasil, a responsabilidade pelas políticas públicas federais de combate ao trabalho infantil é do Ministério de Desenvolvimento Social (MDS) e do Ministério do Trabalho e Emprego (MTE).

12 Sabe-se que a decisão de oferta de trabalho infantil pode ser interdependente da decisão de frequência escolar. No entanto, nesse estudo, o foco recai particularmente sobre o trabalho infantil, tornando a especificação do modelo mais parcimoniosa.
} 
Assumido que $\varepsilon_{g}$ segue uma distribuição normal de probabilidade, é possível estimar os parâmetros do modelo de variável latente (1) e a probabilidade de cada criança trabalhar a partir de um probit usando o método da Máxima Verossimilhança (Wooldridge, 2010).

$$
\operatorname{Pr}\left(Y_{g}=1\right)=\phi\left(X_{g} \beta_{g}\right)
$$

Em (2), $Y_{\mathrm{g}}$ é uma variável indicadora (binária) que assume o valor 1 se a criança trabalha, e 0 em caso contrário, ou seja, $Y_{g}=1 \leftrightarrow Y_{g}^{*}>0$ e $Y_{g}=1 \leftrightarrow Y_{g}^{*} \leq 0$; $\Phi$ é uma função de densidade normal acumulada e $\operatorname{Pr}\left(Y_{g}=1\right)$ é a probabilidade de a criança trabalhar.

A partir do modelo probit é possível mensurar o impacto de pequenas mudanças em cada covariada sobre a probabilidade de trabalho infantil (efeito marginal), permitindo inferências sobre os principais fatores relacionados à entrada precoce de crianças no mercado de trabalho. Destarte, após a estimativa do probit (2), o efeito marginal da covariada $j$ sobre a probabilidade de trabalho infantil é dado pela equação a seguir.

$$
\frac{\partial \operatorname{Pr}\left(Y_{g}=1\right)}{\partial x_{g}^{j}}=\phi\left(\bar{X}_{g} \hat{\beta}_{g}\right) \hat{\beta}_{g}^{i}
$$

Em (3), $\phi$ é uma função de densidade normal; $\bar{X}_{g}$ é a matriz de covariadas tomada na média; $x_{g}^{j}$ é a covariada $j$ contida na matriz $X_{g} ; \hat{\beta}_{g}$ é o vetor estimado de parâmetros do modelo (1) e $\hat{\beta}_{g}^{j}$ é o j-ésimo parâmetro estimado e contido no vetor $\hat{\beta}_{g}$ (exceto intercepto).

\subsection{ESTIMANDO O EFEITO DA ESTRUTURA FAMILIAR}

A questão de maior interesse desse estudo é investigar a importância da estrutura da família na determinação do trabalho infantil no Brasil. Nesse sentido, uma técnica apropriada para mensurar o efeito em destaque é a decomposição de diferenças de probabilidade por grupos. Yun (2004) desenvolveu um método para decompor a diferença de probabilidades entre dois grupos considerando a contribuição de diferenças entre covariadas (diferenças entre atributos observados) e de diferenças entre coeficientes (diferença entre comportamentos dos grupos). A técnica do referido autor é uma extensão aplicada a modelos de resposta binária do tradicional método de decomposição de Blinder-Oaxaca ${ }^{13}$, considerando pesos consistentes para a contribuição de cada característica observada e cada efeito de coeficiente.

13 Ver Blinder (1973) e Oaxaca (1973). 
De modo a tornar mais claro o método de Yun (2004), considere, inicialmente, a diferença média de probabilidade de trabalho infantil para crianças de famílias do grupo A (monoparental chefiada pela mãe) e do grupo B (biparental chefiada pelo pai), já estimadas pelo modelo probit(2) e conforme a equação abaixo.

$$
\bar{Y}_{A}-\bar{Y}_{B}=\left[\overline{\Phi\left(X_{A} \hat{\beta}_{A}\right)}-\Phi \overline{\left(X_{B} \hat{\beta}_{A}\right)}\right]+\left[\Phi \overline{\left(X_{B} \hat{\beta}_{A}\right)}-\Phi \overline{\left(X_{B} \hat{\beta}_{B}\right)}\right]
$$

Em (4), $\bar{Y}_{A}$ e $\bar{Y}_{B}$ são as médias de probabilidade para famílias do tipo A e B, respectivamente; $\Phi \overline{\left(X_{A} \hat{\beta}_{A}\right)}$ é a média amostral de probabilidades individuais preditas considerando características do grupo A e parâmetros estimados para o mesmo grupo; $\Phi \overline{\left(X_{A} \hat{\beta}_{A}\right)}$ é a média de probabilidade com características do grupo A e parâmetros estimados para o grupo A, isto é, a probabilidade contrafatual de uma criança da família $\mathrm{B}$ trabalhar caso estivesse em uma família do grupo $\mathrm{A} ; \Phi\left(\overline{X_{B} \hat{\beta}_{B}}\right)$ é a média amostral de probabilidade predita levando em conta características do grupo B e parâmetros estimados para o referido grupo.

É importante ressaltar que a primeira parcela da equação (4) mensura a diferença de probabilidade de trabalho infantil explicada pelo hiato em características observadas - diferença justificada -, enquanto a segunda parte da referida equação capta a parcela da diferença de probabilidade imputada à desigualdade entre características não observadas e relacionadas ao comportamento dos dois grupos, isto é, a parcela explicada pela diferença de estrutura familiar.

No intuito de obter pesos apropriados para contribuição de cada atributo e coeficiente na diferença de probabilidade intergrupo, Yun (2004) primeiro avalia a função de densidade normal acumulada $\Phi$ na média das características observadas por grupos e, em seguida, usa uma aproximação de Taylor de $1^{\text {a }}$ ordem para obter a seguinte equação de decomposição com pesos específicos para cada atributo observado e coeficiente estimado:

$\bar{Y}_{A}-\bar{Y}_{B}=\sum_{j=1}^{j=K} W_{\Delta x}^{j}\left[\overline{\Phi\left(X_{A} \beta_{A}\right)}-\Phi \overline{\left(X_{B} \beta_{A}\right)}\right]+\sum_{j=1}^{j=K} W_{\Delta \beta}^{j}\left[\overline{\Phi\left(X_{B} \beta_{A}\right)}-\Phi \overline{\left(X_{B} \beta_{B}\right)}\right]$

$\operatorname{Em}(5), W_{\Delta x}^{j}=\frac{\left(\bar{x}_{A}^{j}-\bar{x}_{B}^{j}\right) \hat{\beta}_{\hat{A}}^{j}}{\left(\bar{X}_{A}-\bar{X}_{B}\right) \hat{\beta}_{A}}$ é o peso da característica $j$ na explicação da diferença de probabilidade justificada pelo hiato de atributos observados entre os grupos; $W_{\Delta \beta}^{j}=\frac{\bar{x}_{B}^{j}\left(\hat{\beta}_{A}^{j}-\hat{\beta}_{B}^{j}\right)}{\bar{X}_{B}\left(\hat{\beta}_{A}-\hat{\beta}_{B}\right)}$ é a importância do coeficiente $j$ na explicação da diferença de probabilidade atribuída à inequidade de coeficientes estimados para os dois grupos; $\sum_{j=1}^{j=K} W_{\Delta x}^{j}=\sum_{j=1}^{j=K} W_{\Delta \beta}^{j}=1$ assegura que a soma dos pesos totaliza $1 ; \hat{\beta}_{A}$ e $\hat{\beta}_{B}$ são, res- 
pectivamente, vetores de parâmetros estimados para os grupos A e B; $\bar{X}_{A}$ e $\bar{X}_{B}$ são matrizes com características médias dos grupos $\mathrm{A}$ e $\mathrm{B}$ sequencialmente; $\bar{x}_{A}^{j}$ e $\bar{x}_{B}^{j}$ são médias do atributo $j$ para os grupos em destaque; $\hat{\beta}_{A}^{j}$ e $\hat{\beta}_{B}^{j}$ são os coeficientes estimados para os grupos no tocante à característica $j^{14}$.

\subsection{BASE DE DADOS E SELEÇÃO AMOSTRAL}

Os dados utilizados na análise empírica desse estudo são oriundos do Censo Demográfico de 2010 do Instituto Brasileiro de Geografia e Estatística (IBGE). Ao contrário da Pesquisa Nacional por Amostra de Domicílios (PNAD), o Censo abrange todos os municípios brasileiros e sua amostragem não se caracteriza por processos de conglomeração estratificação (amostra complexa). Dessa forma, os dados censitários permitem a criação de variáveis proxies referentes à demanda e à estrutura do mercado de trabalho de cada município, além de fornecer uma amostra bastante superior à da PNAD, justificando, por conseguinte, seu uso nessa pesquisa.

As questões do Censo Demográfico de 2010 abordam um conjunto de características socioeconômicas referentes aos entrevistados e aos domicílios. Em particular, a questão referente à posição do entrevistado no domicílio permite identificá-lo como responsável, cônjuge ou filho do responsável. Portanto, a partir da identificação de cada domicílio entrevistado, torna-se possível caracterizar a presença de filhos, suas características e aquelas referentes aos seus pais.

O primeiro recorte aplicado à amostra censitária foi desconsideração de pessoas residentes nas zonas rurais. Vale ressaltar que o foco de análise desse estudo é o trabalho infantil no meio urbano do Brasil, pois se sabe que em áreas rurais a atividade laboral de crianças pode estar associada a fatores de ordem cultural e/ou à produção agrícola, não caracterizando, necessariamente, a opção pelo trabalho infantil em razão de um retorno econômico esperado. Portanto, considerando apenas residentes no meio urbano, foram identificadas crianças entre 10 e 14 anos de idade, sem qualquer deficiência física e/ou mental e que se caracterizam como filhos da pessoa responsável

\footnotetext{
${ }^{14}$ Cabe ressaltar que os resultados da decomposição podem ser sensíveis à escolha da categoria de referências quando há covariadas binárias para múltiplas categorias no modelo. Yun (2005) mostra que esse problema é resolvido por meio do cálculo de uma normalização que pode identificar o intercepto e os coeficientes de um conjunto de variáveis binárias, incluindo os grupos de referência. $\mathrm{O}$ cálculo é feito tomando-se a média das estimativas obtidas pela permuta entre os grupos de referência. Para maiores detalhes, vide Yun (2005).
} 
pelo domicílio ${ }^{15}$. Essa faixa etária foi escolhida porque concentra cerca de $95 \%$ do trabalho infantil no Brasil e por caracterizar maior dependência dos filhos em relação aos seus pais. Ademais, trata-se de um corte comum em estudos empíricos sobre o tema (Emerson e Portela Souza, 2005; Ferreira Batista e Cacciamali, 2007; Aquino et al., 2010). Já dentre os responsáveis pelos domicílios, foram considerados apenas as pessoas entre 25 e 65 anos de idade e economicamente ativas (que se achavam ocupadas ou procurando emprego na semana de referência do Censo) ${ }^{16}$.

A Tabela 4 apresenta a distribuição amostral das famílias (total de responsáveis) pré-selecionadas no meio urbano com filho(s) de 10 a 14 anos de idade segundo o gênero do responsável e a presença de cônjuge. Vale lembrar que a família biparental foi caracterizada nesse estudo como aquela em que o responsável convive com seu cônjuge no domicílio, enquanto a família monoparental foi identificada pela ausência do cônjuge no domicílio. Os dados permitem observar que, entre os domicílios monoparentais, a maior frequência são os de mulheres responsáveis (90\%), enquanto nas famílias biparentais, de homens chefes (73\%). Esses dois tipos de família são os mais representativos e respondem juntos por $77 \%$ das famílias com crianças entre 10 e 14 anos residentes no meio urbano do Brasil. Portanto, foram considerados esses dois perfis de famílias: a biparental chefiada pelo pai e a monoparental pela mãe.

Tabela 4 - Brasil: distribuição das famílias segundo gênero do responsável e por presença de cônjuge - apenas residentes no meio urbano e domicílio com presença de filho

\begin{tabular}{|c|c|c|c|}
\hline \multirow{2}{*}{ Responsável } & \multicolumn{2}{|c|}{ Tipo de família (presença de cônjuge) } & \multirow{2}{*}{ Total } \\
\hline & Monoparental (sem cônjuge) & Biparental (com cônjuge) & \\
\hline \multirow[t]{2}{*}{ Mulher } & 165.454 & 183.569 & 349.023 \\
\hline & $89,9 \%$ & $26,7 \%$ & $40,0 \%$ \\
\hline \multirow[t]{2}{*}{ Homem } & 18.682 & 504.563 & 523.245 \\
\hline & $10,2 \%$ & $73,3 \%$ & $60,0 \%$ \\
\hline \multirow[t]{2}{*}{ Total } & 184.136 & 688.132 & 872.268 \\
\hline & $100 \%$ & $100 \%$ & $100 \%$ \\
\hline
\end{tabular}

Fonte: Elaboração própria com base nos microdados do Censo Demográfico de 2010.

15 A criança trabalhadora é aquela que na semana de referência do Censo de 2010 trabalhou ao menos 1 hora sendo remunerada em dinheiro, produtos, mercadorias ou benefícios.

16 Optou-se por excluir da amostra os responsáveis economicamente inativos para diminuir potenciais problemas de seletividade amostral. Outros cortes amostrais também foram convenientes. Primeiro, permaneceram na amostra apenas domicílios onde há uma diferença mínima de 15 anos de idade entre o pai (mãe) responsável e a criança, excluindo, assim, algumas observações com possíveis erros de imputação de idade. Os responsáveis que não responderam às questões sobre cor da pele (raça) e escolaridade foram excluídos da amostra. Por fim, aqueles domicílios com renda per capita superior a R\$25.000,00 foram excluídos da amostra. 
Após todas as filtragens reportadas nessa seção, a amostra final ficou composta por 639.965 crianças residentes no Brasil urbano, sendo 133.308 (21\%) em lares monoparentais e 506.657 (79\%) em biparentais.

Para avaliar os determinantes do trabalho infantil foram consideradas, enquanto variáveis explicativas, as seguintes características: gênero da criança, idade, cor da pele, educação do responsável, número de irmãos por gênero e faixa etária, taxa de desemprego municipal de homens adultos com baixa instrução e taxa de informalidade municipal; um conjunto de variáveis binárias por faixa de população urbana de cada município, assim como para unidades federativas. Vale ressaltar que a escolha dessas variáveis é consoante com a literatura empírica pertinente (Duryea e Arends-Kuenning, 2003; Kassouf, 2005; Ferreira Batista e Cacciamali, 2007). A descrição detalhada das referidas variáveis está no apêndice (Tabela A.1).

\section{RESULTADOS}

\subsection{TRABALHO INFANTIL E CARACTERÍSTICAS DAS FAMÍLIAS}

As características familiares, sobretudo dos pais, são importantes condicionantes do trabalho infantil, dado que a decisão de inserir o filho no mercado de trabalho é tomada pelo responsável. Na literatura especializada, destacam-se alguns fatores, tais como: renda domiciliar, educação dos pais, tamanho da família e tipo de família (Grootaert e Patrinos, 2002; Kassouf, 2005; Kassouf, 2007; Ferreira Batista e Cacciamali, 2007). Nesta subseção são apresentadas características dos pais, de acordo com a estrutura familiar e a condição de trabalho dos filhos, conforme pode ser observado na Tabela 5. Por outro lado, também são registradas informações sobre o perfil das crianças inseridas no mercado de trabalho no Brasil urbano, na Tabela 6. As referidas características são baseadas na amostra selecionada para a subsequente análise empírica.

A Tabela 5 apresenta a distribuição dos responsáveis pelo domicílio segundo um conjunto de atributos observados (raça, instrução, idade, condição de atividade econômica, localização, renda domiciliar, tamanho da família) e por tipo de família (monoparental chefiada pela mãe e biparental chefiada pelo pai) e condição de trabalho de ao menos um dos filhos entre 10 e 14 anos de idade no meio urbano do Brasil. Dentro de cada grupo familiar foram realizados testes de diferença de proporções e de diferença de médias entre lares onde nenhuma criança trabalha e lares onde ao menos uma criança trabalha.

Dentre os chefes de domicílio cujos filhos trabalham, verifica-se uma maior concentração de pais que se declararam pardos ou brancos, a despeito do tipo de família. 
Por outro lado, nota-se a menor concentração de pais de cor branca nos lares onde as crianças trabalham. Quanto ao nível de escolaridade, observa-se uma forte concentração de pais sem instrução e com nível fundamental incompleto, sobretudo em domicílios em que os filhos trabalham. Já nos domicílios onde as crianças não trabalham, há maior frequência de pais com nível médio de instrução completo e superior incompleto, assim como de pais com nível superior completo. Tais diferenças chamam atenção para o possível papel do capital humano dos pais na determinação da inserção da criança no mercado de trabalho.

Tabela 5 - Brasil: características do responsável pelo domicílio por tipo de família e condição de trabalho de ao menos um dos filhos

\begin{tabular}{|c|c|c|c|c|}
\hline \multirow[b]{2}{*}{ Raça } & \multicolumn{2}{|c|}{ Monoparental chefiada pela mãe } & \multicolumn{2}{|c|}{ Biparental chefiada pelo pai } \\
\hline & $\begin{array}{l}\text { Filhos não } \\
\text { trabalham }\end{array}$ & $\begin{array}{c}\text { Filhos } \\
\text { trabalham }\end{array}$ & $\begin{array}{l}\begin{array}{l}\text { Filhos não } \\
\text { trabalham }\end{array} \\
\end{array}$ & $\begin{array}{c}\text { Filhos } \\
\text { trabalham }\end{array}$ \\
\hline Branca & $41,7 \%$ & $38,1 \%$ & $48,7 \%$ & $46,6 \%$ \\
\hline Preta & $10,2 \%$ & $11,7 \%$ & $8,3 \%$ & $9,0 \%$ \\
\hline Parda & $46,5 \%$ & $48,5 \%$ & $41,9 \%^{*}$ & $43,0 \%$ \\
\hline Vermelha ou amarela & $1,6 \%$ & $1,8 \%$ & $1,2 \%$ & $1,3 \%$ \\
\hline \multicolumn{5}{|l|}{ Instrução } \\
\hline Sem instrução e fundamental incompleto & $51,2 \%$ & $66,1 \%$ & $50,5 \%$ & $65,0 \%$ \\
\hline Fundamental completo e médio incompleto & $17,3 \%$ & $15,9 \%$ & $17,3 \%^{*}$ & $16,5 \%$ \\
\hline Médio completo e superior incompleto & $23,2 \%$ & $14,9 \%$ & $24,2 \%$ & $15,7 \%$ \\
\hline Superior completo & $8,3 \%$ & $3,1 \%$ & $8,0 \%$ & $2,8 \%$ \\
\hline \multicolumn{5}{|l|}{ Atividade Econômica } \\
\hline Inativo & $24,2 \%$ & $18,9 \%$ & $7,9 \%$ & $4,9 \%$ \\
\hline Ativo & $75,8 \%$ & $81,1 \%$ & $92,1 \%$ & $95,1 \%$ \\
\hline \multicolumn{5}{|l|}{ Cidade } \\
\hline Não metrópole & $59,6 \%$ & $69,1 \%$ & $61,9 \%$ & $72,4 \%$ \\
\hline Metrópole & $40,4 \%$ & $30,9 \%$ & $38,1 \%$ & $27,6 \%$ \\
\hline \multicolumn{5}{|l|}{ Região } \\
\hline Norte & $7,5 \%^{*}$ & $7,6 \%$ & $6,9 \%^{*}$ & $7,2 \%$ \\
\hline Nordeste & $27,5 \% *$ & $28,0 \%$ & $24,1 \%$ & $20,9 \%$ \\
\hline Sudeste & $41,5 \%$ & $36,5 \%$ & $43,1 \%$ & $37,6 \%$ \\
\hline Sul & $16,0 \% *$ & $17,0 \%$ & $18,4 \%$ & $22,8 \%$ \\
\hline Centro-Oeste & $7,6 \%$ & $10,9 \%$ & $7,5 \%$ & $11,5 \%$ \\
\hline \multicolumn{5}{|l|}{ Médias } \\
\hline Idade & 39,4 & 41,3 & 41,9 & 43,6 \\
\hline Renda domiciliar per capita & $360,4^{*}$ & 374,1 & $570,8^{*}$ & 588,1 \\
\hline Moradores & 3,8 & 4,3 & 4,6 & 5,0 \\
\hline Beneficiados por programas sociais & 0,7 & 0,8 & 0,4 & 0,5 \\
\hline Observações (total de domicílios) & $\begin{array}{l}157.160 \\
(96,6 \%)\end{array}$ & $\begin{array}{c}5.477 \\
(3,4 \%)\end{array}$ & $\begin{array}{l}479.931 \\
(97,5 \%)\end{array}$ & $\begin{array}{l}12.426 \\
(2,5 \%)\end{array}$ \\
\hline
\end{tabular}

Nota: $\left(^{*}\right)$ A diferença de média (proporção) intragrupo familiar não é estatisticamente significativa a 1\%. A condição de trabalho foi definida pela presença de ao menos um dos filhos no mercado de trabalho.

Fonte: Elaboração própria com base nos microdados do Censo Demográfico de 2010.

A taxa de inatividade econômica dos pais é relativamente mais forte nas famílias monoparentais, especialmente quando não há crianças trabalhando. Provavelmente, 
nesses últimos lares, rendimentos derivados de pensões por morte do cônjuge podem desencorajar tanto o trabalho da mãe quanto de seus filhos. No entanto, parece que a renda do não trabalho deve ser suficientemente elevada para não induzir o trabalho infantil nos domicílios monoparentais, haja vista que a taxa de inatividade das mães solteiras ainda permanece alta quando os filhos trabalham.

No tocante à localização, os lares nos quais as crianças trabalham parecem ser mais concentrados em regiões não metropolitanas, em ambos os tipos de famílias. Já no que se refere à região de residência, o Sudeste tem a maior concentração de domicílios com crianças trabalhadoras, seguido, em geral, pela região Nordeste. Vale observar, contudo, que, comparativamente aos lares onde as crianças não trabalham, a região Sudeste detém menor concentração de domicílios que registram trabalho infantil. Vale também observar que o trabalho infantil ganha força na região Sul, em particular, no caso das famílias biparentais.

Tabela 6 - Brasil: características das crianças no domicílio por tipo de família e condição de trabalho

\begin{tabular}{|c|c|c|c|c|}
\hline & \multicolumn{2}{|c|}{ Monoparental chefiada pela mãe } & \multicolumn{2}{|c|}{ Biparental chefiada pelo pai } \\
\hline & Não trabalha & Trabalha & Não trabalha & Trabalha \\
\hline \multicolumn{5}{|l|}{ Gênero } \\
\hline Menina & $50,6 \%$ & $42,7 \%$ & $48,8 \%$ & $38,4 \%$ \\
\hline Menino & $49,4 \%$ & $57,3 \%$ & $51,2 \%$ & $61,6 \%$ \\
\hline \multicolumn{5}{|l|}{ Idade } \\
\hline 10 anos & $19,0 \%$ & $3,9 \%$ & $21,1 \%$ & $4,6 \%$ \\
\hline 11 anos & $19,0 \%$ & $7,6 \%$ & $20,0 \%$ & $8,4 \%$ \\
\hline 12 anos & $20,0 \%$ & $13,0 \%$ & $20,0 \%$ & $13,3 \%$ \\
\hline 13 anos & $20,7 \%$ & $24,1 \%$ & $19,6 \%$ & $24,5 \%$ \\
\hline 14 anos & $21,3 \%$ & $51,4 \%$ & $19,3 \%$ & $49,2 \%$ \\
\hline \multicolumn{5}{|l|}{ Frequência escolar } \\
\hline Frequenta escola pública & $87,1 \%$ & $81,0 \%$ & $83,4 \%^{*}$ & $83,7 \%$ \\
\hline Frequenta escola particular & $10,0 \%$ & $3,1 \%$ & $14,9 \%$ & $5,3 \%$ \\
\hline Não frequenta, mas já frequentou & $2,4 \%$ & $15,5 \%$ & $1,2 \%$ & $10,6 \%$ \\
\hline Nunca frequentou & $0,6 \%^{*}$ & $0,5 \%$ & $0,5 \%$ * & $0,4 \%$ \\
\hline \multicolumn{5}{|l|}{ Médias } \\
\hline Idade & 12,1 & 13,1 & 12,0 & 13,1 \\
\hline Número de irmãos ( 0 a 5 anos) & 0,11 & 0,09 & 0,13 & 0,10 \\
\hline Número de irmãs ( 0 a 5 anos) & $0,11^{*}$ & 0,10 & 0,13 & 0,11 \\
\hline Número de irmãos (6 a 9 anos) & $0,16^{*}$ & 0,15 & 0,17 & 0,16 \\
\hline Número de irmãs (6 a 9 anos) & $0,15^{*}$ & 0,15 & 0,17 & 0,16 \\
\hline Número de irmãos ( 15 a 17 anos) & 0,16 & 0,19 & 0,15 & 0,20 \\
\hline Número de irmãs (15 a 17 anos) & 0,16 & 0,20 & 0,13 & 0,16 \\
\hline Observações (total de filhos) & $\begin{array}{l}196.169 \\
(97,1 \%)\end{array}$ & $\begin{array}{c}5.791 \\
(2,9 \%)\end{array}$ & $\begin{array}{l}595.467 \\
(97,8 \%)\end{array}$ & $\begin{array}{l}13.332 \\
(2,4 \%)\end{array}$ \\
\hline
\end{tabular}

Notas: (*) A diferença de média (proporção) intragrupo familiar não é estatisticamente significativa a 1\%. A condição de trabalho foi definida pela presença de ao menos um dos filhos no mercado de trabalho.

Fonte: Elaboração própria com base nos microdados do Censo Demográfico de 2010. 
Nos lares onde as crianças trabalham, as médias de idade dos pais e de tamanho da família são maiores. O mesmo pode ser observado no tocante aos beneficiados por programas sociais (inclusive Bolsa Família), com destaque para as famílias monoparentais. Em geral, os participantes desses programas têm um nível de renda baixo, e, portanto, o efeito da renda pode estar superando o do benefício. No tocante à renda domiciliar per capita, a média parece ser maior nas famílias biparentais, embora a diferença de médias não seja estatisticamente significativa entre lares onde as crianças trabalham e lares onde elas não trabalham. Cabe frisar que esse resultado pode não persistir quando controlado por outras características que influenciam na oferta de trabalho infantil pelos pais. As variáveis que captam a renda familiar, a condição de atividade dos pais e a participação em programas sociais não foram inseridas no modelo empírico por se caracterizarem possivelmente interdependentes (endógenas) à decisão de trabalho infantil. Por fim, na análise do total de domicílios, observa-se que o trabalho infantil parece ser mais presente nas famílias monoparentais $(3,4 \%)$, em relação às biparentais $(2,5 \%)$.

A Tabela 6 apresenta a distribuição das crianças nos domicílios selecionados para a análise empírica segundo características de gênero, idade, frequência escolar e número de irmãos e por condição de ocupação e tipo de família no Brasil urbano. Os dados apontam que, entre as crianças trabalhadoras, a maior parcela é de meninos, apesar de o percentual de meninas no mercado de trabalho ser relativamente maior nas famílias monoparentais. Isso pode ser uma indicação da necessidade de a mãe solteira colocar todos os filhos para trabalhar como forma de geração de renda. Nota-se, por outro lado, que o trabalho infantil aumenta consideravelmente com a idade da criança, sobretudo aos 14 anos de idade.

Em relação à frequência escolar, destaca-se o percentual significativo de crianças trabalhadoras que desistiram de estudar, especialmente nas famílias monoparentais ${ }^{17}$. Quanto ao número de irmãos, as crianças que trabalham têm, em média, um número maior de irmãos mais velhos e menor de irmãos mais novos (famílias biparentais). Em linhas gerais, o número de irmãos (irmãs) por faixa etária parece não discriminar fortemente os grupos de famílias.

\footnotetext{
${ }^{17}$ A variável frequência escolar também foi excluída da análise empírica dada sua potencial endogeneidade com a decisão de trabalho infantil.
} 


\subsection{DETERMINANTES DO TRABALHO INFANTIL}

Nesta subseção, são apresentados os resultados do modelo probit para avaliação dos determinantes do trabalho infantil no Brasil urbano. Assume-se que a estrutura familiar altera significativamente os parâmetros do modelo. Portanto, optou-se pela estimação de modelos por amostras separadas segundo a categoria da família. A Tabela 7 apresenta os efeitos marginais sobre a probabilidade de trabalho infantil estimados a partir de regressões por tipo de família. A tabela em análise registra três regressões. $\mathrm{Na}$ coluna (1), tem-se os resultados do modelo representado na equação (1) estimado com a amostra de crianças em famílias monoparentais chefiadas pela mãe. Na coluna (2), são apresentados os resultados da regressão considerando uma amostra de crianças em famílias biparentais sob responsabilidade do pai. Por fim, na coluna (3) são registrados os achados levando em conta a amostra total de crianças e a inclusão de uma dummy para identificação do tipo de família entre as variáveis explicativas do modelo.

Tabela 7 - Efeitos marginais: probabilidade de a criança trabalhar (regressões probit) por tipo de família

\begin{tabular}{|c|c|c|c|}
\hline & $\begin{array}{c}(1) \\
\text { Monoparental chefiada } \\
\text { pela mãe }\end{array}$ & $\begin{array}{l}(2) \\
\text { Biparental chefiada } \\
\text { pelo pai }\end{array}$ & $\begin{array}{c}(3) \\
\text { Ambas }\end{array}$ \\
\hline \multicolumn{4}{|l|}{ Atributos do(a) filho(a) } \\
\hline Menino & $\begin{array}{l}0,0070^{* * *} \\
(0,0006)\end{array}$ & $\begin{array}{l}0,0065^{\star * *} \\
(0,0003)\end{array}$ & $\begin{array}{l}0,0066^{* * *} \\
(0,0003)\end{array}$ \\
\hline Idade & $\begin{array}{l}0,0117^{\star * *} \\
(0,0002)\end{array}$ & $\begin{array}{l}0,0087^{\star * *} \\
(0,0001)\end{array}$ & $\begin{array}{l}0,0094^{* * *} \\
(0,0001)\end{array}$ \\
\hline \multicolumn{4}{|l|}{ Atributos do(a) responsável } \\
\hline Idade & $\begin{array}{l}0,0005^{* * *} \\
(0,0000)\end{array}$ & $\begin{array}{l}0,0003^{* * *} \\
(0,0000)\end{array}$ & $\begin{array}{l}0,0003^{* * *} \\
(0,0000)\end{array}$ \\
\hline Negro(a) & $\begin{array}{l}0,0025^{\star *} \\
(0,0011)\end{array}$ & $\begin{array}{l}0,0019^{* * *} \\
(0,0006)\end{array}$ & $\begin{array}{l}0,0021^{* * *} \\
(0,0005)\end{array}$ \\
\hline Pardo(a) & $\begin{array}{c}0,0001 \\
(0,0007)\end{array}$ & $\begin{array}{c}0,0001 \\
(0,0003)\end{array}$ & $\begin{array}{c}0,0001 \\
(0,0003)\end{array}$ \\
\hline Vermelho(a) ou amarelo(a) & $\begin{array}{c}0,0036 \\
(0,0026)\end{array}$ & $\begin{array}{c}0,0026^{*} \\
(0,0015)\end{array}$ & $\begin{array}{l}0,0029^{* *} \\
(0,0013)\end{array}$ \\
\hline Fund. completo e médio incompleto & $\begin{array}{l}-0,0031^{\star * *} \\
(0,0009)\end{array}$ & $\begin{array}{l}-0,0023^{* * *} \\
(0,0004)\end{array}$ & $\begin{array}{l}-0,0025^{\star * *} \\
(0,0004)\end{array}$ \\
\hline Médio comp. e superior incompleto & $\begin{array}{l}-0,0086^{\star * *} \\
(0,0008)\end{array}$ & $\begin{array}{l}-0,0065^{\star * *} \\
(0,0004)\end{array}$ & $\begin{array}{l}-0,0070^{* * *} \\
(0,0003)\end{array}$ \\
\hline Superior completo & $\begin{array}{l}-0,0160^{\star * *} \\
(0,0008)\end{array}$ & $\begin{array}{l}-0,0120^{\star * *} \\
(0,0004)\end{array}$ & $\begin{array}{l}-0,0130^{* * *} \\
(0,0004)\end{array}$ \\
\hline Composição da família & & & \\
\hline Número de irmãos ( 0 a 5 anos) & $\begin{array}{l}-0,0012 \\
(0,0010)\end{array}$ & $\begin{array}{l}-0,0007 \\
(0,0004)\end{array}$ & $\begin{array}{l}-0,0008^{* *} \\
(0,0004)\end{array}$ \\
\hline Número de irmãs ( 0 a 5 anos) & $\begin{array}{l}0,0020^{\star *} \\
(0,0009) \\
(0,0008)\end{array}$ & $\begin{array}{l}0,0011^{\star *} \\
(0,0004) \\
(0,0004)\end{array}$ & $\begin{array}{l}0,0013^{\star * *} \\
(0,0004) \\
(0,0003)\end{array}$ \\
\hline
\end{tabular}


Tabela 7 - Efeitos marginais: probabilidade de a criança trabalhar (regressões probit) por tipo de família (continuação)

\begin{tabular}{|c|c|c|c|}
\hline & $\begin{array}{c}(1) \\
\text { Monoparental chefiada } \\
\text { pela mãe }\end{array}$ & $\begin{array}{c}(2) \\
\text { Biparental chefiada } \\
\text { pelo pai }\end{array}$ & $\begin{array}{c}(3) \\
\text { Ambas }\end{array}$ \\
\hline Número de irmãs (6 a 9 anos) & $\begin{array}{l}0,0024^{* * *} \\
(0,0008)\end{array}$ & $\begin{array}{c}0,0005 \\
(0,0004)\end{array}$ & $\begin{array}{l}0,0009^{* *} \\
(0,0003)\end{array}$ \\
\hline Número de irmãos (15 a 17 anos) & $\begin{array}{c}0,0013^{*} \\
(0,0007)\end{array}$ & $\begin{array}{l}0,0024^{* * *} \\
(0,0004)\end{array}$ & $\begin{array}{l}0,0021^{\star * *} \\
(0,0003)\end{array}$ \\
\hline Número de irmãs (15 a 17 anos) & $\begin{array}{l}0,0027^{* * *} \\
(0,0007)\end{array}$ & $\begin{array}{l}0,0013^{* * *} \\
(0,0004)\end{array}$ & $\begin{array}{l}0,0016^{* * *} \\
(0,0003)\end{array}$ \\
\hline \multicolumn{4}{|l|}{ Mercado de trabalho } \\
\hline Taxa de desemprego & $\begin{array}{l}-0,0514^{* * *} \\
(0,0072)\end{array}$ & $\begin{array}{l}-0,0297^{* * *} \\
(0,0037)\end{array}$ & $\begin{array}{l}-0,0348^{* * *} \\
(0,0033)\end{array}$ \\
\hline Taxa de informalidade & $\begin{array}{l}0,0167^{* * *} \\
(0,0035)\end{array}$ & $\begin{array}{l}0,0183^{* * *} \\
(0,0017)\end{array}$ & $\begin{array}{l}0,0176^{\star * *} \\
(0,0016)\end{array}$ \\
\hline \multicolumn{4}{|l|}{ Localização } \\
\hline Metrópole & $\begin{array}{l}-0,0018^{* *} \\
(0,0008)\end{array}$ & $\begin{array}{l}-0,0020^{* * *} \\
(0,0004)\end{array}$ & $\begin{array}{l}-0,0020^{* * *} \\
(0,0004)\end{array}$ \\
\hline População de 5.001 a 10.000 hab & $\begin{array}{c}0,0018 \\
(0,0013)\end{array}$ & $\begin{array}{l}-0,0001 \\
(0,0006)\end{array}$ & $\begin{array}{c}0,0002 \\
(0,0005)\end{array}$ \\
\hline População de 10.001 a 20.000 hab & $\begin{array}{c}0,0012 \\
(0,0013)\end{array}$ & $\begin{array}{c}0,0007 \\
(0,0006)\end{array}$ & $\begin{array}{c}0,0007 \\
(0,0005)\end{array}$ \\
\hline População de 20.001 a 50.000 hab & $\begin{array}{l}-0,0009 \\
(0,0013)\end{array}$ & $\begin{array}{l}-0,0009 \\
(0,0006)\end{array}$ & $\begin{array}{l}-0,0010^{*} \\
(0,0006)\end{array}$ \\
\hline População de 50.001 a 100.000 hab & $\begin{array}{l}-0,0018 \\
(0,0014)\end{array}$ & $\begin{array}{l}-0,0035^{* * *} \\
(0,0006)\end{array}$ & $\begin{array}{l}-0,0032^{\star * *} \\
(0,0006)\end{array}$ \\
\hline População de 100.001 a 500.000 hab & $\begin{array}{l}-0,0052^{\star * *} \\
(0,0012)\end{array}$ & $\begin{array}{l}-0,0038^{* * *} \\
(0,0006)\end{array}$ & $\begin{array}{l}-0,0042^{* * *} \\
(0,0005)\end{array}$ \\
\hline População com mais de 500.000 hab & $\begin{array}{l}-0,0031^{*} \\
(0,0016)\end{array}$ & $\begin{array}{l}-0,0028^{* * *} \\
(0,0008)\end{array}$ & $\begin{array}{l}-0,0029^{* * *} \\
(0,0007)\end{array}$ \\
\hline Rondônia & $\begin{array}{l}0,0119^{* * *} \\
(0,0040)\end{array}$ & $\begin{array}{l}0,0049^{* * *} \\
(0,0018)\end{array}$ & $\begin{array}{l}0,0066^{\star * *} \\
(0,0017)\end{array}$ \\
\hline Acre & $\begin{array}{l}-0,0017 \\
(0,0035)\end{array}$ & $\begin{array}{l}-0,0044^{\star *} \\
(0,0022)\end{array}$ & $\begin{array}{l}-0,0037^{\star \star} \\
(0,0018)\end{array}$ \\
\hline Amazonas & $\begin{array}{l}-0,0035 \\
(0,0024)\end{array}$ & $\begin{array}{l}-0,0045^{* * *} \\
(0,0012)\end{array}$ & $\begin{array}{l}-0,0041^{\star * *} \\
(0,0011)\end{array}$ \\
\hline Roraima & $\begin{array}{c}0,0009 \\
(0,0059)\end{array}$ & $\begin{array}{l}-0,0032 \\
(0,0028)\end{array}$ & $\begin{array}{l}-0,0022 \\
(0,0025)\end{array}$ \\
\hline Pará & $\begin{array}{l}-0,0009 \\
(0,0019)\end{array}$ & $\begin{array}{l}-0,0044^{* * *} \\
(0,0009)\end{array}$ & $\begin{array}{l}-0,0035^{\star * *} \\
(0,0008)\end{array}$ \\
\hline Amapá & $\begin{array}{l}-0,0040 \\
(0,0035)\end{array}$ & $\begin{array}{l}-0,0065^{* * *} \\
(0,0019)\end{array}$ & $\begin{array}{l}-0,0058^{\star * *} \\
(0,0016)\end{array}$ \\
\hline Tocantins & $\begin{array}{c}0,0007 \\
(0,0026)\end{array}$ & $\begin{array}{l}-0,0027^{* *} \\
(0,0012)\end{array}$ & $\begin{array}{l}-0,0019^{*} \\
(0,0011)\end{array}$ \\
\hline Maranhão & $\begin{array}{l}-0,0024 \\
(0,0018)\end{array}$ & $\begin{array}{l}-0,0066^{\star * *} \\
(0,0008)\end{array}$ & $\begin{array}{l}-0,0056^{\star * *} \\
(0,0008)\end{array}$ \\
\hline Piauí & $\begin{array}{l}-0,0048^{* *} \\
(0,0019)\end{array}$ & $\begin{array}{l}-0,0068^{* * *} \\
(0,0009)\end{array}$ & $\begin{array}{l}-0,0063^{* * *} \\
(0,0008)\end{array}$ \\
\hline
\end{tabular}


Tabela 7 - Efeitos marginais: probabilidade de a criança trabalhar (regressões probit) por tipo de família (continuação)

\begin{tabular}{|c|c|c|c|}
\hline & $\begin{array}{c}(1) \\
\text { Monoparental chefiada } \\
\text { pela mãe }\end{array}$ & $\begin{array}{l}\text { (2) } \\
\text { Biparental chefiada } \\
\text { pelo pai }\end{array}$ & $\begin{array}{c}\text { (3) } \\
\text { Ambas }\end{array}$ \\
\hline Ceará & $\begin{array}{l}-0,0000 \\
(0,0017)\end{array}$ & $\begin{array}{l}-0,0051^{\star * *} \\
(0,0008)\end{array}$ & $\begin{array}{l}-0,0038^{* * *} \\
(0,0007)\end{array}$ \\
\hline Rio Grande do Norte & $\begin{array}{l}-0,0061^{\star * *} \\
(0,0019)\end{array}$ & $\begin{array}{l}-0,0073^{\star * *} \\
(0,0008)\end{array}$ & $\begin{array}{l}-0,0070^{* * *} \\
(0,0008)\end{array}$ \\
\hline Paraíba & $\begin{array}{l}-0,0023 \\
(0,0019)\end{array}$ & $\begin{array}{l}-0,0049^{* * *} \\
(0,0009)\end{array}$ & $\begin{array}{l}-0,0042^{* * *} \\
(0,0008)\end{array}$ \\
\hline Pernambuco & $\begin{array}{c}0,0024 \\
(0,0017)\end{array}$ & $\begin{array}{l}-0,0033^{* * *} \\
(0,0009)\end{array}$ & $\begin{array}{l}-0,0018^{* *} \\
(0,0008)\end{array}$ \\
\hline Alagoas & $\begin{array}{l}-0,0019 \\
(0,0022)\end{array}$ & $\begin{array}{l}-0,0058^{\star * *} \\
(0,0010)\end{array}$ & $\begin{array}{l}-0,0048^{* * *} \\
(0,0009)\end{array}$ \\
\hline Sergipe & $\begin{array}{l}-0,0045^{\star *} \\
(0,0022)\end{array}$ & $\begin{array}{l}-0,0062^{\star * *} \\
(0,0012)\end{array}$ & $\begin{array}{l}-0,0057^{* * *} \\
(0,0010)\end{array}$ \\
\hline Bahia & $\begin{array}{c}0,0028^{*} \\
(0,0016)\end{array}$ & $\begin{array}{l}-0,0036^{\star * *} \\
(0,0008)\end{array}$ & $\begin{array}{l}-0,0019^{* * *} \\
(0,0007)\end{array}$ \\
\hline Minas Gerais & $\begin{array}{l}0,0042^{\star * *} \\
(0,0011)\end{array}$ & $\begin{array}{c}0,0010^{*} \\
(0,0006)\end{array}$ & $\begin{array}{l}0,0018^{* * *} \\
(0,0005)\end{array}$ \\
\hline Espírito Santo & $\begin{array}{c}0,0036 \\
(0,0024)\end{array}$ & $\begin{array}{l}-0,0011 \\
(0,0011)\end{array}$ & $\begin{array}{c}0,0001 \\
(0,0010)\end{array}$ \\
\hline Rio de Janeiro & $\begin{array}{l}-0,0033^{* * *} \\
(0,0013)\end{array}$ & $\begin{array}{l}-0,0051^{* * *} \\
(0,0007)\end{array}$ & $\begin{array}{l}-0,0046^{* * *} \\
(0,0006)\end{array}$ \\
\hline Paraná & $\begin{array}{l}0,0082^{* * *} \\
(0,0016)\end{array}$ & $\begin{array}{l}0,0072^{* * *} \\
(0,0008)\end{array}$ & $\begin{array}{l}0,0075^{* * *} \\
(0,0007)\end{array}$ \\
\hline Santa Catarina & $\begin{array}{l}0,0069^{* * *} \\
(0,0021)\end{array}$ & $\begin{array}{l}0,0091^{* * *} \\
(0,0011)\end{array}$ & $\begin{array}{l}0,0087^{\star * *} \\
(0,0010)\end{array}$ \\
\hline Rio Grande do Sul & $\begin{array}{c}0,0000 \\
(0,0013)\end{array}$ & $\begin{array}{l}0,0019^{* *} \\
(0,0008)\end{array}$ & $\begin{array}{l}0,0014^{\star *} \\
(0,0007)\end{array}$ \\
\hline Mato Grosso do Sul & 0,0043 & 0,0021 & $0,0026^{* *}$ \\
\hline & $(0,0027)$ & $(0,0014)$ & $(0,0012)$ \\
\hline Mato Grosso & 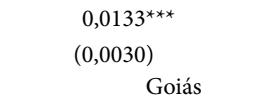 & $\begin{array}{l}0,0059^{* * *} \\
(0,0014)\end{array}$ & $\begin{array}{l}0,0076^{* * *} \\
(0,0013)\end{array}$ \\
\hline Goiás & $\begin{array}{l}0,0176^{* * *} \\
(0,0023)\end{array}$ & $\begin{array}{l}0,0118^{* * *} \\
(0,0011)\end{array}$ & $\begin{array}{l}0,0132^{* * *} \\
(0,0010)\end{array}$ \\
\hline Distrito Federal & $\begin{array}{c}0,0014 \\
(0,0043)\end{array}$ & $\begin{array}{l}-0,0069^{* * *} \\
(0,0018)\end{array}$ & $\begin{array}{l}-0,0042^{\star *} \\
(0,0018)\end{array}$ \\
\hline Biparental (chefiada pelo pai) & & & $\begin{array}{l}-0,0055^{* * *} \\
(0,0003)\end{array}$ \\
\hline Predições corretas & $97,1 \%$ & $97,8 \%$ & $97,6 \%$ \\
\hline Probabilidade de a criança trabalhar & 0,0293 & 0,0218 & 0,0236 \\
\hline Observações & 201.960 & 608.799 & 810.759 \\
\hline
\end{tabular}

Notas: Desvios-padrão robustos à heteroscedasticidade ao agrupamento de crianças por domicílio entre parênteses. ${ }^{* * *}$ ) Estatisticamente significante a $1 \%$. ${ }^{* *}$ ) Estatisticamente significante a $5 \%$. (*) Estatisticamente significante a $10 \%$.

Fonte: Elaboração própria com base nos microdados do Censo Demográfico de 2010. 
Em geral, os resultados são consoantes com aqueles encontrados na literatura especializada (Duryea e Arends-Kuenning, 2003; Kassouf, 2005; Emerson e Portela Souza, 2007; Ferreira Batista e Cacciamali, 2007; Aquino et al., 2010). No tocante às características das crianças, por exemplo, nota-se que o gênero é um importante determinante do trabalho infantil, uma vez que os meninos são mais propensos ao trabalho em relação às meninas. Esse resultado persiste entre as estruturas familiares estudadas. Quanto à idade das crianças, os dados apontam uma relação positiva com a probabilidade de trabalhar, de maior intensidade nas famílias monoparentais, onde um ano a mais de idade aumenta em 1,2 p.p a probabilidade de trabalho, enquanto nos lares biparentais, o aumento estimado é de 0,88 p.p. Há evidências, em estudos feitos para o Brasil, que relacionam o aumento do trabalho infantil com a idade. Tal fato, geralmente, é associado a melhores oportunidades de emprego e de remuneração, e, por conseguinte, ao alto custo de oportunidade da dedicação exclusiva da criança aos estudos (Emerson e Portela Souza, 2007; Aquino et al., 2010; Cacciamali, Ferreira Batista e Tatei, 2011).

Quanto às características dos pais, a idade aumenta a probabilidade de trabalho dos filhos, isto é, pais mais velhos registram maior chance de oferta de mão de obra dos filhos. Com relação à raça do responsável pelo domicílio, apenas a categoria negro(a) apresentou significância estatística. Tal resultado indica que a probabilidade de trabalho infantil aumenta entre os filhos de pais que se autodeclaram negros em relação aos brancos; evidência similar entre as categorias de família em análise.

Em relação ao nível de educação dos pais, importante determinante do trabalho infantil, os resultados mostram que quanto maior a instrução do responsável, menor a probabilidade de trabalhar dos filhos. Tal efeito é maior nas famílias monoparentais. Por exemplo, comparado a ser filho de mãe sem instrução (categoria omitida), um filho de mãe solteira com curso superior completo tem probabilidade de trabalhar 1,6 p.p menor. No caso de filho em domicílio biparental, o referido efeito da escolaridade do responsável reduz em 1,2 p.p a probabilidade de trabalho infantil. Ou seja, pais mais instruídos tendem a não encaminhar os filhos ao mercado de trabalho, e quando a mãe responsável vive sem companheiro, esse efeito parece ser mais intenso (Grootaert e Patrinos, 2002; Kassouf, 2005; Kassouf, 2010; Cacciamali, Ferreira Batista e Tatei, 2011). Em linhas gerais, a educação pode ser considerada uma proxy do nível de renda dos pais, expondo indiretamente a relação inversa entre a renda familiar e o trabalho infantil.

Há outro resultado interessante no tocante ao número de irmãos no domicílio por faixa etária. Nota-se que um maior número de irmãos mais novos, em especial do sexo feminino, aumenta a probabilidade de trabalho da criança, principalmente para aquelas inseridas em famílias monoparentais chefiadas pela mãe (Kassouf, 2005; Emerson e Portela Souza, 2008; Aquino et al., 2010). Quanto ao número de irmãos mais velhos, a despeito do gênero, a probabilidade de trabalhar da criança aumenta nos dois tipos de família. Essas variáveis captam o efeito do tamanho da família, que segundo a lite- 
ratura, tem correlação negativa com o trabalho infantil. Em suma, quanto maior o número de membros na família, menor a renda per capita e mais vulnerável é a família quanto às condições econômicas (Barros, Mendonça e Velazco, 1994; Kassouf, 2010; Cacciamali, Ferreira Batista e Tatei, 2011).

Os fatores relacionados à demanda do mercado de trabalho apresentaram significância estatística nos três modelos. Quanto à taxa de desemprego para adultos de baixa instrução ${ }^{18}$ (atratividade do mercado de trabalho do município), os dados sugerem uma correlação negativa com o trabalho infantil. Espera-se que quanto maior for essa taxa de desemprego, menor é a atratividade do mercado para o trabalho infantil. Desse modo, as evidências encontradas se revelaram consistentes com os achados de Duryea e Arends-Kuenning (2003), por exemplo. Com relação ao nível de informalidade do mercado de trabalho, as evidências mostraram que a taxa de informalidade tem uma correlação positiva com o trabalho infantil (Neves e Menezes, 2010). Dado que, no Brasil, o trabalho infantil é legalizado apenas para maiores de 16 anos, os setores informais podem oferecer mais oportunidades de emprego para as crianças, representando uma importante força ao lado da demanda.

As características de localização também apresentaram relação com a probabilidade de trabalho infantil. Por exemplo, residir em região metropolitana reduz a probabilidade de trabalho infantil em cerca de 0,3 p.p.. Quanto aos estados, residir no Maranhão, Piauí, Rio Grande do Norte ou Rio de Janeiro reduz a probabilidade de trabalho infantil em comparação a morar em São Paulo, a despeito da estrutura familiar. Já para famílias que residem nos estados da Paraíba, Pernambuco, Bahia ou Alagoas, a referida correlação é semelhante, contudo, apenas estatisticamente significativa para as famílias biparentais. Ademais, residir no Paraná, Santa Catarina ou Rio Grande do Sul aumenta a probabilidade de trabalho infantil em relação a residir em São Paulo, mas para o Rio Grande do Sul só há diferença estatística nas famílias biparentais. Os resultados não mostram um padrão quanto ao efeito da renda, isto é, regiões mais pobres têm menor proporção de trabalho infantil no meio urbano. Por outro lado, em alguns estados pode prevalecer o efeito da atratividade do mercado de trabalho, que é mais intenso em regiões mais desenvolvidas.

O Gráfico 2 apresenta a relação entre probabilidade de trabalho infantil no Brasil e renda domiciliar per capita por tipo de família, que não foi inserida no modelo esta-

\footnotetext{
18 A variável taxa de desemprego inserida nesse modelo é uma proxy para o desemprego infantil. A variável foi criada considerando os adultos do sexo masculino, com baixa instrução (sem instrução ou Ensino Fundamental incompleto) e com idade entre 30 e 35 anos. Supõe-se que os adultos com essas características competem com as crianças no mercado de trabalho. A intuição é de que quando a taxa de desemprego está alta, os adultos terão preferência na ocupação desses postos de trabalho em relação às crianças, reduzindo o trabalho infantil.
} 
tístico devido ao problema de endogeneidade. Para tanto, considerando as predições individuais de probabilidade por tipo de família (monoparental chefiada pela mãe e biparental chefiada pelo pai), conforme as estimativas apresentadas nas colunas (1) e (2) da tabela anterior, tomaram-se as médias amostrais de tais probabilidades e da renda domiciliar per capita segundo 100 quantis da distribuição de renda.

\section{Gráfico 2 - Brasil urbano: relação entre probabilidade predita de a criança trabalhar segundo a renda domiciliar per capita e por tipo de família.}

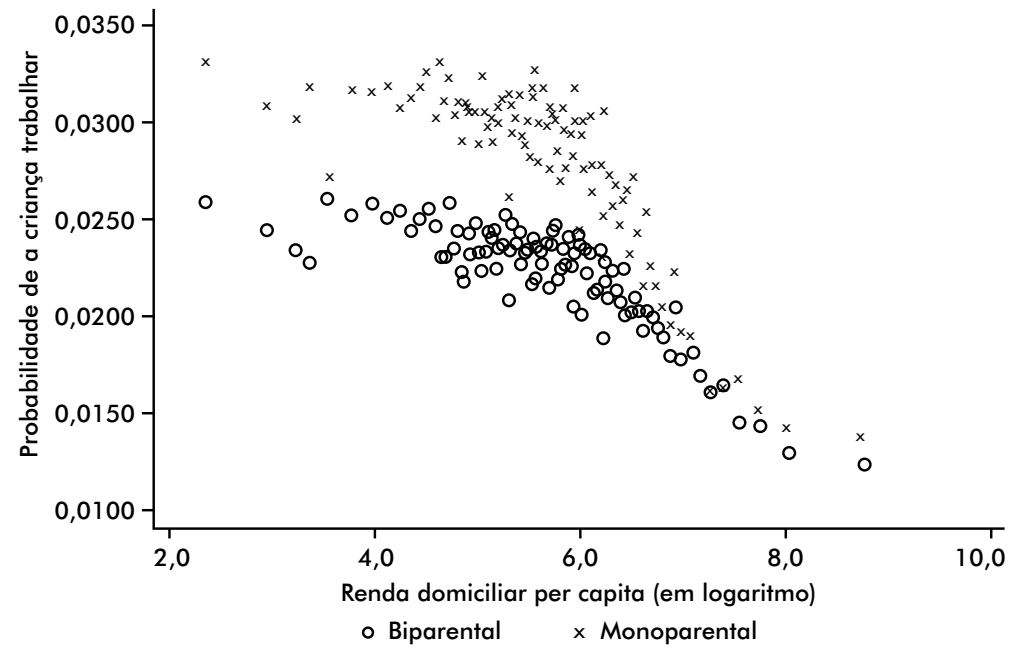

Fonte: Elaboração própria com base nos microdados do Censo Demográfico de 2010.

É interessante observar que há uma relação inversa (não linear) entre probabilidade de trabalho infantil e renda familiar, evidenciando a importância da condição de pobreza no favorecimento do fenômeno em destaque. Por outro lado, mesmo com o aumento do nível de renda, há uma persistência na diferença de probabilidade por tipo de família, isto é, após controlar um conjunto de características individuais condicionantes do trabalho infantil, observa-se que, em uma família monoparental chefiada pela mãe, há maior chance de a criança trabalhar quando comparada a uma família biparental chefiada pelo pai sob mesmo padrão de renda. Essa diferença apenas desaparece quando a renda familiar é suficientemente elevada ${ }^{19}$. No intuito de

\footnotetext{
19 Embora não reportado no Gráfico 2, em razão da escala logarítmica para a renda, estimou-se que para níveis de renda domiciliar per capita superiores a aproximadamente $\mathrm{R} \$ 850,00$, a diferença de probabilidade de trabalho infantil entre grupos de famílias sofre forte redução. Isto é, aquém da renda média de $\mathrm{R} \$ 850,00$, a diferença média da probabilidade em destaque é de 0,62 p.p, enquanto acima é de 0,12 p.p.
} 
reforçar tal evidência, a próxima subseção apresenta uma análise mais detalhada do efeito da estrutura familiar sobre a probabilidade média do trabalho infantil através da decomposição dos efeitos de atributos observáveis e não observáveis relacionados às famílias.

\subsection{TRABALHO INFANTIL E ESTRUTURA FAMILIAR}

A Tabela 8 apresenta os resultados obtidos a partir da decomposição da diferença de probabilidade de trabalho infantil por tipo de família. Os dados mostram que, após considerar o efeito de várias características observadas referentes aos atributos das crianças, pais, tamanho da família, mercado de trabalho e localização, há uma diferença positiva de probabilidade de trabalho infantil entre famílias monoparentais chefiadas pela mãe e biparentais sob responsabilidade do pai. Embora tal diferença tenha pequena magnitude ${ }^{20}(0,67$ p.p), ela sugere que uma criança em família monoparental é relativamente mais propensa à entrada precoce no mercado de trabalho.

Cabe também observar que a diferença de comportamento entre os tipos de famílias responde por quase a totalidade $(110 \%)$ do referido hiato de probabilidade, enquanto a diferença justificada pelos atributos médios tem importância de apenas $-10 \%$. Destarte, se os dois grupos de famílias em análise registrassem atributos médios iguais, a diferença de probabilidade de trabalho infantil aumentaria em cerca de 0,07 p.p, por um lado, e se as famílias monoparentais apresentassem o mesmo comportamento médio das família biparentais em atributos não observados, o hiato de probabilidade seria reduzido em cerca de 0,75 p.p. Portanto, apesar de os efeitos reportados se revelarem assimétricos, a diferença de probabilidade de trabalho infantil é fortemente associada a distintos comportamentos entre os tipos de famílias.

As características observadas que mais explicam a diferença de probabilidade infantil entre os grupos de família são a idade do(a) pai(mãe) responsável pelo domicílio $(-48,8 \%)$, a idade da criança $(46,7 \%)$, diferenças de inserção no mercado de trabalho municipal - taxa de desemprego de adultos com baixa instrução no município (-5,7\%) - e taxa de informalidade $(5,4 \%)$ e gênero da criança $(-4,3 \%)$, respectivamente. De forma mais específica, os resultados sugerem que, se a diferença de idade entre uma mãe típica em uma família monoparental e um pai em uma família biparental fosse

\footnotetext{
${ }^{20}$ Tal evidência é consistente com as baixas proporções de crianças trabalhadoras observadas no Brasil urbano.
} 
eliminada, a diferença de probabilidade de trabalho infantil entre tais grupos aumentaria em cerca de 0,33 p.p. Caso também fossem exauridas as diferenças intergrupos em termos de idade da criança, taxa de desemprego de adultos poucos instruídos, taxa de informalidade e gênero da criança, os respectivos impactos sobre o hiato de probabilidade seriam: redução de 0,32 p.p , aumento de 0,04 p.p, redução de 0,04 p.p e aumento de 0,03 p.p.

Tabela 8 - Decomposição de diferença de probabilidade de a criança trabalhar família monoparental chefiada pela mãe contra família biparental chefiada pelo pai

\begin{tabular}{|c|c|c|c|c|}
\hline & \multicolumn{2}{|c|}{$\begin{array}{c}\text { Diferença em Atributos } \\
\text { Observados (E) }\end{array}$} & \multicolumn{2}{|c|}{$\begin{array}{c}\text { Diferença nos } \\
\text { Coeficientes (C) }\end{array}$} \\
\hline & Coeficiente & Importância (\%) & Coeficiente & Importância (\%) \\
\hline \multicolumn{5}{|l|}{ Atributos do(a) filho(a) } \\
\hline Menino & $-0,0002940^{* * *}$ & $-4,3327$ & $-0,0010084^{* *}$ & $-14,8600$ \\
\hline Idade & $0,0031664^{* * *}$ & 46,6620 & 0,0055374 & 81,6020 \\
\hline \multicolumn{5}{|l|}{ Responsável } \\
\hline Idade & $-0,0033102^{* * *}$ & $-48,7810$ & $0,0106040^{* * *}$ & 156,2700 \\
\hline $\operatorname{Branco}(\mathrm{a})$ & $0,0002436^{\star}$ & 3,5902 & $-0,0000499$ & $-0,7360$ \\
\hline Negro(a) & 0,0000434 & 0,6394 & 0,0000016 & 0,0235 \\
\hline Pardo(a) & $-0,0001495^{\star}$ & $-2,2036$ & $-0,0000033$ & $-0,0483$ \\
\hline Vermelho(a) ou amarelo(a) & 0,0000149 & 0,2192 & 0,0000012 & 0,0171 \\
\hline Sem instrução e fund. incompleto & $0,0002178^{* * *}$ & 3,2099 & 0,000074 & 1,0910 \\
\hline Fund. completo e médio incompleto & $0,0000275^{* * *}$ & 0,4056 & 0,0000126 & 0,1861 \\
\hline Médio comp. e superior incompleto & 0,000018 & 0,2654 & 0,000012 & 0,1775 \\
\hline Superior completo & $0,0000156^{* * *}$ & 0,2305 & $-0,0000197$ & $-0,2905$ \\
\hline \multicolumn{5}{|l|}{ Composição da família } \\
\hline Número de irmãos (0 a 5 anos) & 0,0000496 & 0,7303 & $-0,0000396$ & $-0,5836$ \\
\hline Número de irmãs (0 a 5 anos) & $-0,0000866^{* *}$ & $-1,2756$ & 0,0000904 & 1,3324 \\
\hline Número de irmãos (6 a 9 anos) & $-0,0000363$ & $-0,5356$ & 0,0001234 & 1,8178 \\
\hline Número de irmãs (6 a 9 anos) & $-0,0000670^{* * *}$ & $-0,9879$ & $0,0003603^{\star *}$ & 5,3096 \\
\hline Número de irmãos (15 a 17 anos) & $0,0000384^{*}$ & 0,5665 & $-0,0003507^{\star *}$ & $-5,1674$ \\
\hline Número de irmãs (15 a 17 anos) & $0,0001644^{* * *}$ & 2,4231 & 0,0001865 & 2,7476 \\
\hline \multicolumn{5}{|l|}{ Mercado de Trabalho } \\
\hline Taxa de desemprego & $-0,0003886^{* * *}$ & $-5,7260$ & $-0,0007761$ & $-11,4370$ \\
\hline Taxa de informalidade & $0,0003689^{* * *}$ & 5,4366 & $-0,0037586^{*}$ & $-55,3880$ \\
\hline \multicolumn{5}{|l|}{ Localização } \\
\hline Metrópole & $-0,0001784^{\star * *}$ & $-2,6283$ & 0,0003602 & 5,3078 \\
\hline Rondônia & $0,0000030^{* * *}$ & 0,0442 & 0,0000055 & 0,0818 \\
\hline Acre & $-0,0000177$ & $-0,2609$ & $-0,0000018$ & $-0,0271$ \\
\hline Amazonas & $0,0000199^{*}$ & 0,2937 & $-0,0000251$ & $-0,3704$ \\
\hline Roraima & $-0,0000055$ & $-0,0807$ & $-0,0000004$ & $-0,0060$ \\
\hline Pará & $0,0000106^{*}$ & 0,1556 & 0,000044 & 0,6489 \\
\hline Amapá & $-0,0000184$ & $-0,2710$ & 0,0000054 & 0,0796 \\
\hline Tocantins & $-0,0000006$ & $-0,0088$ & 0,0000016 & 0,0232 \\
\hline Maranhão & $-0,0000096^{* *}$ & $-0,1410$ & $0,0001257^{*}$ & 1,8527 \\
\hline Piauí & $0,0000055^{\star * *}$ & 0,0814 & 0,0000168 & 0,2474 \\
\hline Ceará & $-0,0000199$ & $-0,2931$ & $0,0001636^{* *}$ & 2,4113 \\
\hline
\end{tabular}


Tabela 8 - Decomposição de diferença de probabilidade de a criança trabalhar família monoparental chefiada pela mãe contra família biparental chefiada pelo pai (continuação)

\begin{tabular}{lcccc}
\hline & \multicolumn{2}{c}{$\begin{array}{c}\text { Diferença em Atributos } \\
\text { Observados (E) }\end{array}$} & \multicolumn{2}{c}{$\begin{array}{c}\text { Diferença nos } \\
\text { Coeficientes (C) }\end{array}$} \\
\cline { 2 - 5 } & Coeficiente & Importância (\%) & Coeficiente & Importância (\%) \\
\hline Rio Grande do Norte & $0,0000431^{* * *}$ & 0,6353 & $-0,000003$ & $-0,0442$ \\
Paraíba & $0,0000067^{*}$ & 0,0983 & 0,0000075 & 0,1103 \\
Pernambuco & 0,0000145 & 0,2142 & $0,0001392^{*}$ & 2,0508 \\
Alagoas & $-0,0000104$ & $-0,1532$ & 0,0000523 & 0,7708 \\
Sergipe & $-0,0000349^{* *}$ & $-0,5137$ & 0,0000000 & 0,0002 \\
Bahia & 0,0000554 & 0,8166 & $0,0002734^{* * *}$ & 4,0283 \\
Minas Gerais & $-0,0000433^{* * *}$ & $-0,6374$ & $-0,0002131$ & $-3,1404$ \\
Espírito Santo & 0,0000058 & 0,0853 & 0,000015 & 0,2213 \\
Rio de Janeiro & $-0,0001378^{* * *}$ & $-2,0312$ & $-0,0000363$ & $-0,5345$ \\
São Paulo & 0,0000214 & 0,3158 & $-0,0011319^{* * *}$ & $-16,6800$ \\
Paraná & $-0,0002193^{* * *}$ & $-3,2323$ & $-0,0003616^{* * *}$ & $-5,3281$ \\
Santa Catarina & $-0,0001861^{* * *}$ & $-2,7431$ & $-0,0003898^{* * *}$ & $-5,7446$ \\
Rio Grande do Sul & 0,0000000 & 0,0001 & $-0,0005105^{* * *}$ & $-7,5225$ \\
Mato Grosso do Sul & $0,0000109^{*}$ & 0,1604 & $-0,0000388$ & $-0,5719$ \\
Mato Grosso & $-0,0000522^{* * *}$ & $-0,7692$ & 0,0000186 & 0,2737 \\
Goiás & $-0,0000291^{* * *}$ & $-0,4291$ & $-0,0000702$ & $-1,0347$ \\
Distrito Federal & 0,0000085 & 0,1259 & $0,0000655^{*}$ & 0,9646 \\
Intercepto & & & $-0,0020017$ & $-29,4980$ \\
\hline Subtotal & $-0,0007213^{* * *}$ & $-10,6301$ & $0,0075072^{* * *}$ & 110,6340 \\
\hline Total (E+C) & $0,006785^{* * *}$ & 100 & & \\
\hline
\end{tabular}

Notas: Desvios-padrão robustos à heteroscedasticidade entre parênteses. $(* * *)$ Estatisticamente significante a $1 \%$. $(* *)$ Estatisticamente significante a $5 \%$. (*) Estatisticamente significante a $10 \%$.

Fonte: Elaboração própria com base nos microdados do Censo Demográfico de 2010

Os dados estatisticamente significativos da Tabela 8 também sugerem que diferenças comportamentais entre famílias monoparentais e biparentais relacionadas à idade do responsável (156,3\%), à informalidade no mercado de trabalho (-55,4\%), à residência no estado de São Paulo e ao gênero da criança $(-14,9 \%)$ são bastante relevantes para a explicação da diferença de probabilidade de trabalho infantil imputada às características não observadas. Em particular, se mães responsáveis em famílias monoparentais com mesma média de idade de pais chefes de famílias biparentais apresentassem comportamento semelhante aos últimos, a diferença de probabilidade de trabalho infantil entre esses grupos seria reduzida em 1,06 p.p. Já se as crianças do sexo masculino nos dois grupos de famílias registrassem comportamento homogêneo, o hiato médio de probabilidade de trabalho infantil entre famílias monoparentais e biparentais aumentaria em cerca de 0,10 p.p. Ademais, caso famílias biparentais e monoparentais em municípios com mesma taxa de informalidade fossem iguais em comportamentos não observados, a diferença de propensão ao trabalho infantil entre os grupos aumentaria em 0,37 p.p., e caso residissem no estado de São Paulo, a referida diferença seria 0,11 p.p maior. 


\section{CONCLUSÃO}

O trabalho infantil é um problema social que tem consequências de longo prazo na vida das crianças, pois além dos problemas de saúde e de desempenho escolar, pode favorecer menores salários na fase adulta. No Brasil, apesar da redução no número de crianças trabalhando nas últimas décadas, o problema ainda persiste em todos os estados do país. Nesse cenário, este artigo procurou investigar os determinantes do trabalho infantil no Brasil urbano, com atenção especial para os possíveis efeitos atrelados à estrutura familiar.

Ao se cotejarem as características dos pais (mães) e filhos (de 10 a 14 anos) por famílias biparentais sob responsabilidade do pai e monoparentais chefiadas pela mãe, foi possível constatar importantes diferenças entre os referidos grupos. Primeiro, os meninos com idade próxima aos 14 anos são mais propensos à entrada precoce no mercado de trabalho. As meninas são mais tendenciosas ao trabalho infantil quando residem em lar com mãe solteira. $\mathrm{O}$ trabalho infantil é muito favorecido em lares cujos pais não têm instrução ou possuem Ensino Fundamental incompleto; em cidades não metropolitanas; na região Sudeste; em domicílios com maior número de moradores e onde o(a) responsável é mais velho(a). Ao contrário das crianças que não trabalham, aquelas inseridas no mercado de trabalho tendem a abandonar a escola com bastante frequência; fato que potencializa os efeitos nocivos do trabalho infantil durante a vida adulta.

Os resultados empíricos reforçaram a importância das características supracitadas, em especial destacam-se como fatores indutores do trabalho infantil o sexo masculino, a maior idade da criança e a baixa escolaridade dos pais. Uma maior taxa de empregos informais no meio urbano do município de residência e uma menor taxa de desemprego de pessoas de baixa instrução são importantes fatores, ao lado da demanda, que favorecem o aumento do trabalho infantil. Após considerar o efeito das características acima juntamente com outros condicionantes observados do trabalho infantil, verificou-se uma relação inversa e não linear entre renda domiciliar per capita e probabilidade de trabalho infantil. Ademais, os resultados mostram que crianças em famílias monoparentais sob chefia da mãe são mais propensas ao trabalho que aquelas em domicílio biparentais sob responsabilidade do pai com similar padrão de renda. Essa diferença de probabilidade apenas é eliminada quando a renda da família alcança níveis elevados para reduzir consideravelmente a chance de trabalho infantil. A decomposição da diferença de probabilidade de trabalho infantil por tipo de família reforçou esse último achado ao revelar que a probabilidade média de a criança ingressar no mercado de trabalho é relativamente maior em lares cuja mãe responsável é solteira. Quase a totalidade dessa diferença de probabilidade entre famílias monoparentais e biparentais é explicada por distintos comportamentos entre 
esses grupos, sobretudo atitudes não observadas e relacionadas à idade do(a) pai(mãe), à idade da criança, ao gênero da criança e a diferenças regionais de inserção no mercado de trabalho.

Para erradicar o trabalho infantil de forma efetiva, os resultados do presente estudo sugerem políticas de combate à pobreza no longo prazo, como geração de emprego e renda. Em particular, no tocante às políticas públicas de distribuição de renda, deve ser dada maior atenção às famílias monoparentais chefiadas por mulheres. Outras formas de combate ao trabalho infantil seriam políticas de qualificação dos pais, intensificação das ações de fiscalização e punição efetiva para os empresários/autônomos que empregam crianças menores de 14 anos, políticas para reduzir o grau de informalidade do mercado de trabalho e a maior conscientização da sociedade quanto aos impactos do trabalho infantil sobre a educação, saúde e nível de renda futuro das crianças.

\section{REFERÊNCIAS}

AMATO, P. R. Children's adjustment to divorce: Theories, hypotheses, and empirical support. Journal of Marriage and the Family, v. 55, n. 1, p. 23-58, 1993.

AQUINO, J. M.; FERNANDES, M. M.; PAZELLO, E. T.; SCORZAFAVE, L. G. Trabalho infantil: Persistência intergeracional e decomposição da incidência entre 1992 e 2004 no Brasil rural e urbano. Revista de Economia Contemporânea, Rio de Janeiro, v. 14, n. 1, p. 61-84, 2010.

BALAND, J. M.; ROBINSON, J. A. Is child labor inefficient? Journal of Political Economy, v. 104, n. 4, p. 663-679, 2000.

BARROS, R. P; MENDONÇA, R., VELAZCO, T. Is poverty the main cause of child work in urban Brazil? Texto para Discussão, IPEA, n. 351, 1994.

BASU, K.; VAN, P. H. The economics of child labor. American Economic Review, v. 88, n. 3, p. 412-427, 1998.

BASU, K. Child Labor: Causes, consequence, and cure, with remarks on international labor standards. Journal of Economic Literature, v. 37, n. 3, p. 1083-117, 1999.

BEEGLE, K.; DEHEJIA, R. H.; GATTI, R.; KRUTIKOVA, S. The consequences of child labor: evidence from longitudinal data in rural Tanzania. In: Child Labor Conference, Indiana University, 2007.

BHALOTRA, S.; HEADY, C. Child farm labor: the wealth paradox. The World Bank economic review, v. 17, n. 2, p. 197-227, 2003.

BIBLARZ, T. J.; GOTTAINER, G. Family Structure and Children's Success: a Comparison of Widowed and Divorced Single-Mother Families. Journal of Marriage and the Family, v. 62, n. 2, p. 533-548, 2000.

BLINDER, A. S. Wage discrimination: reduced form and structural estimates. Journal of Human Resources, n. 8, p. 436-455, 1973. 
CACCIAMALI, M. C.; FERREIRA BATISTA, N. N. Migração familiar, trabalho infantil e ciclo intergeracional da pobreza no estado de São Paulo. In: Encontro regional da ABET, 6, 2007, Paraíba. Anais... João Pessoa: ABET, 2007.

CACCIAMALI, M. C.; FERREIRA BATISTA, N. N.; TATEI, F. Trabalho infantil e o status ocupacional dos pais. Revista de Economia Política, v. 28, n. 2, p. 269-290, 2008.

CACCIAMALI, M. C.; FERREIRA BATISTA, N. N.; TATEI, F. Padrões familiares de utilização de trabalho infantil. Revista ABET, v. 10, n. 1, p. 11-34, 2011.

CARLOTO, C. M. A chefia familiar feminina nas famílias monoparentais em situação de extrema pobreza. Revista Virtual Textos e Contextos, v. 4, n. 4, 2005.

CAVALIERI, C.H. O impacto do trabalho infantil sobre o desempenho escolar: uma avaliação para o Brasil metropolitano. Tese de Doutorado, Escola de Administração de Empresas de São Paulo, Fundação Getúlio Vargas, São Paulo, SP, 2002.

DEGRAFF, D. S.; BILSBORROW, R. E. Female-headed households and family welfare in rural Ecuador. Journal of Population Economics, v. 6, n. 4, p. 317-336, 1993.

DEGRAFF, D. S.; LEVISON, D.; ROBISON, M. Child Labor and Mothers' Work in Brazil. International Journal of Sociology and Social Policy, v. 29, n. 3/4, p. 152-163, 2009.

DEGRAFF, D. S.; LEVISON, D.; FERRO, A. Kids at risk: children's employment in hazardous occupations in Brazil. Estudos Econômicos, v. 44, n. 4, p. 685-721, 2014.

DURYEA, S.; ARENDS-KUENNING, M. School attendance, child labor and local labor market fluctuations in urban Brazil. World Development, v. 31, n. 7, p. 1.165-1.178, 2003.

DURYEA, S.; SEDLACEK, G.; ILAHI, N.; SASAKI, M. Child Labor, Schooling and Poverty in Latin America. Social protection Discussion Paper Series, World Bank, n. 0511, 2005.

EDMONDS, E.; TURK, C. Child labor in transition in Vietnam. Policy Research Working Paper Series, World Bank, n. 2774, 2002.

EDMONDS, E. V. Child Labor. NBER Working Paper, n. 12926, 2007.

EMERSON, P. M.; PORTELA SOUZA, A. F. The inter-generational Persistence of Child Labor. Social Protection Discussion Paper Series, World Bank, n. 0515, 2005.

EMERSON, P. M.; PORTELA SOUZA, A. F. Child Labor, School Attendance, and Intrahousehold Gender Bias in Brazil. The World Bank Economic Review, v. 21, n. 2, p. 301-316, 2007.

EMERSON, P. M.; PORTELA SOUZA, A. F. Birth Order, Child Labor, and School Attendance in Brazil. World Development, v. 36, n. 9, p. 1647-1664, 2008.

FIALHO, R. C. B. Enfoques sociais da família monoparental. Dissertação de Mestrado, Programa de Pós-Graduação em Economia, Universidade Federal da Paraíba, João Pessoa, PB, 2004.

FRANKLIN, R. N. et al. Trabalho precoce e riscos à saúde. Adolescência Latino-americana, v. 2, n. 2, p. 80-89, 2001.

GALLI, R. The economic impact of child labor. Discussion Paper, ILO, Geneva, 2001.

GROOTAERT, C.; KANDUR, R. Child labor: an economic perspective. International Labour Review, v. 132, n. 2, p. 187-203, 1995. 
GROOTAERT, C.; PATRINOS, H. A. A four-country comparative study of child labor. In: The Economics of Child Labor, International Seminar, World Bank, Oslo, 2002.

HEADY, C. The effect of child labor on learning achievement. World Development, v. 31, n. 2, p. 385-398, 2003.

HILL, M. S.; DUNCAN, G. Parental family income and the socioeconomic attainment of children. Social Science Research, n. 16, p. 39-73, 1987.

HOFFMANN, R.; LEONE, E. T. Participação da mulher no mercado de trabalho e desigualdade da renda domiciliar per capita no Brasil: 1981-2002. Nova Economia, v. 14, n. 2, p. 35-58, 2004.

ILAHI, N. P.; ORAZEM, P. F.; SEDLACEK, G. The implications of child labor for adult wages, income and poverty: retrospective evidence from Brazil. Unpublished Working Paper, Washington D. C.: The World Bank, 2000.

KASSOUF, A. L. Trabalho infantil no Brasil. Tese de Livre Docência, Escola Superior de Agricultura Luiz de Queiroz da Universidade de São Paulo, Piracicaba, 1999.

KASSOUF, A. L. Trabalho infantil: causas e consequências. Estudo realizado para apresentação no concurso de Professor Titular. São Paulo: Departamento de Economia, Administração e Sociologia da ESALQ, USP, 2005.

KASSOUF, A. L. O que conhecemos sobre o trabalho infantil? Revista Nova Economia. Belo Horizonte, v. 17, n. 2, p. 323-350, 2007.

KASSOUF, A. L. Trabalho infantil no meio rural brasileiro: evidências sobre o "paradoxo da riqueza”. Economia Aplicada, v. 14, n. 3, p. 339-353, 2010.

MANSKI, C. F. et al. Alternative Estimates of the Effect of Family Structure During Adolescence on High School Graduation. Journal of the American Statistical Association, v. 87, n. 417, p. 25-37, 1992.

MCLANAHAN, S.; BUMPASS, L. Intergenerational Consequences of Family Disruption. American Journal of Sociology, v. 94, n. 1, p. 130-152, 1988.

MCLANAHAN, S.; SANDEFUR, G. Growing up with a single parent: what hurts and what helps. Cambridge: Harvard University Press, 1994.

MINAYO-GOMEZ, C.; MEIRELLES, Z. V. Crianças e adolescentes trabalhadores: um compromisso para a saúde coletiva. Cadernos de Saúde Pública, v. 13, n. 2, p. 135-140, 1997.

MOEHLING, C. M. Family structure, school attendance, and child labor in the American South in 1900 and 1910. Explorations in Economic History, v. 41, n. 1, p. 73-100, 2004.

NEVES, E. C. J.; MENEZES, T. A. de. Bolsa Família, crises econômicas e trabalho infantil: diferentes impactos no Nordeste e Sudeste. In: Encontro Nacional da ENABER, 13, 2010, Minas Gerais. Anais... Belo Horizonte: ENABER, 2010.

NICOLELLA, A.; KASSOUF, A. L.; BARROS, A. L. M. O Impacto do Trabalho Infantil no Setor Agrícola Sobre a Saúde. Revista Brasileira de Economia e Sociologia Rural, v. 46, n. 3, p. 673-701, 2008.

OAXACA, R. Male-female wage differentials in urban labor markets. International Economic Review, n. 14, p. 693-709, 1973. 
PATRINOS, A. H.; PSACHAROPOUlOS, G. Family Size, Schooling and Child Labor in Peru: An empirical analysis. Journal of Population Economics, v. 10, n. 4, p. 387-405, 1997.

RAY, R. Child labor, child schooling, and their interaction with adult labor: empirical evidence for Peru and Pakistan. The World Bank Economic Review, n. 14, p. 347-371, 2000.

REPÓRTER BRASIL. Meia Infância: desafios ao combate do trabalho infantil. São Paulo: Repórter Brasil, 2012. Disponível em: <http://reporterbrasil.org.br/trabalhoinfantil $\geq$. Acesso em: 13 set. 2013.

RUSHTON, W.; MCLANAHAN, S. Father Absence and Child Well-being: a Critical Review. Center for Research on Child Wellbeing, Princeton University, 2002.

SORJ, B.; FONTES, A. Famílias Monoparentais femininas, pobreza e o bem-estar das crianças: comparações inter-regionais. Mimeo, 2008.

THOMAS, D. Like father, like son; like mother, like daughter: parental resources and child height. The Journal of Human Resources, v. 29, n. 4, p. 950-988, 1994.

UNICEF. The state of the world's children 2011: adolescence, an age of opportunity. Nova York: Fundo das Nações Unidas para a Infância, 2011.

VITALE, M. A. F. Família monoparentais: indagações. Revista Serviço Social e Sociedade, n. 71, ano XXIII, 2002.

WOOLDRIDGE, J. Introdução à econometria: uma abordagem moderna. São Paulo: Cengage Learning, 2010.

YUN, M. Decomposing differences in the first moment. Economics Letters, n. 82, p. 275-280, 2004.

YUN, M. A simple solution to the identification problem in detailed wage decompositions. Economic Inquiry, v. 43, p. 766-772, 2005. 


\section{APÊNDICE}

\section{Tabela A.1 - Descrição das variáveis utilizadas na análise empírica dos determinantes do trabalho infantil}

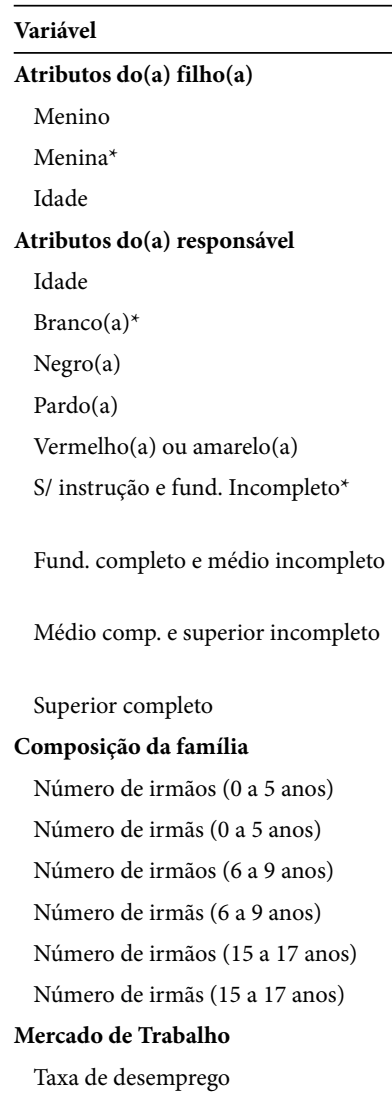

Taxa de informalidade

\section{Definição}

Gênero da criança ( 1 - menino e 0 caso contrário)

Gênero da criança ( 1 - menina e 0 caso contrário)

Idade da criança em anos

Idade do responsável (pai ou mãe) em anos

1- se declara branco(a); 0 caso contrário

1- se declara negro(a); 0 caso contrário

1- se declara pardo(a); 0 caso contrário

1- se declara vermelho(a) ou amarelo(a); 0 caso contrário

1 - para indivíduos sem instrução e com nível fundamental incompleto; 0 caso contrário

1 - para indivíduos com nível fundamental completo e médio incompleto; 0 caso contrário

1 - para indivíduos com nível médio completo e superior incompleto; 0 caso contrário

1 - para indivíduos com nível superior completo; 0 caso contrário

Quantidade de irmãos no domicílio por gênero e faixa etária

Taxa de desemprego municipal para adultos de baixa instrução - o número de desempregados no município de residência da criança (aqueles que não trabalham e estavam procurando emprego na semana de referência) pelo número de indivíduos economicamente ativos (aqueles que trabalham em atividades remuneradas ou não), considerando na amostra, adultos do sexo masculino com idade entre 30 e 35 anos e escolaridade entre 0 e 4 anos de estudo.

Taxa de informalidade do mercado de trabalho - número de trabalhadores em atividades informais no município de residência da criança (trabalhador doméstico e empregado sem carteira de trabalho assinada, aprendiz ou estagiário sem remuneração, não remunerado em ajuda a membro do domicílio, conta própria e trabalhador na produção para o próprio consumo, todos sem contribuição previdenciária) dividido pelo número de total de trabalhadores no meio urbano.

1 - se o município de residência é uma região metropolitana; 0 caso contrário 


\section{Tabela A.1 - Descrição das variáveis utilizadas na análise empírica dos determinantes do trabalho infantil (continuação)}

\begin{tabular}{ll}
\hline Variável & Definição \\
\hline Não metrópole & $\begin{array}{l}1-\text { se o município de residência não é uma região metropolitana; } \\
0 \text { caso contrário }\end{array}$ \\
$\begin{array}{ll}\text { Rondônia, Acre, Amazonas, Roraima, Pará, } \\
\text { Amapá, Tocantins, Maranhão, Piauí, Ceará, } \\
\text { Rio Grande do Norte, Paraíba, Pernambuco, } \\
\text { contrário }\end{array}$ \\
$\begin{array}{ll}\text { Alagoas, Sergipe, Bahia, Minas Gerais, Espírito } \\
\text { Catarina, Rio de Jio Grande em um dos referidos estados e } 0 \text { caso }\end{array}$ \\
$\begin{array}{ll}\text { Sul, Mato Grosso, Goiás e Distrito Federal } \\
\text { Trabalha (variável dependente) }\end{array}$ \\
$\begin{array}{ll}1-\text { se a criança trabalha de forma remunerada em dinheiro, produtos, } \\
\text { mercadorias ou benefícios; } 0 \text { caso contrário. }\end{array}$ \\
\hline
\end{tabular}

Nota: ${ }^{*}$ ) Categoria omitida.

Fonte: Elaboração própria com base em microdados do Censo Demográfico de 2010. 
Tabela A.2 - Coeficientes estimados - regressões probit por tipo de família

\begin{tabular}{|c|c|c|c|}
\hline & $\begin{array}{c}(1) \\
\text { Monoparental chefiada } \\
\text { pela mãe }\end{array}$ & $\begin{array}{c}(2) \\
\text { Biparental chefiada } \\
\text { pelo pai }\end{array}$ & $\begin{array}{c}(3) \\
\text { Ambas }\end{array}$ \\
\hline \multicolumn{4}{|l|}{ Atributos do(a) filho(a) } \\
\hline Menino & $\begin{array}{l}0,1493^{* * *} \\
(0,0123)\end{array}$ & $\begin{array}{l}0,1831^{* * *} \\
(0,0079)\end{array}$ & $\begin{array}{l}0,1731^{* * *} \\
(0,0066)\end{array}$ \\
\hline Idade & $\begin{array}{l}0,2537^{* * *} \\
(0,0053)\end{array}$ & $\begin{array}{l}0,2458^{\star * *} \\
(0,0033)\end{array}$ & $\begin{array}{l}0,2480^{* * *} \\
(0,0028)\end{array}$ \\
\hline \multicolumn{4}{|l|}{ Atributos do(a) responsável } \\
\hline Idade & $\begin{array}{l}0,0114^{* * *} \\
(0,0010)\end{array}$ & $\begin{array}{l}0,0070^{* * *} \\
(0,0006)\end{array}$ & $\begin{array}{l}0,0082^{* * *} \\
(0,0005)\end{array}$ \\
\hline Negro(a) & $\begin{array}{l}0,0519^{* *} \\
(0,0221)\end{array}$ & $\begin{array}{l}0,0498^{* * *} \\
(0,0155)\end{array}$ & $\begin{array}{l}0,0505^{* * *} \\
(0,0126)\end{array}$ \\
\hline Pardo(a) & $\begin{array}{c}0,0029 \\
(0,0147)\end{array}$ & $\begin{array}{c}0,0012 \\
(0,0094)\end{array}$ & $\begin{array}{c}0,0011 \\
(0,0079)\end{array}$ \\
\hline Vermelho(a) ou amarelo(a) & $\begin{array}{c}0,0715 \\
(0,0492)\end{array}$ & $\begin{array}{c}0,0680^{*} \\
(0,0376)\end{array}$ & $\begin{array}{l}0,0693^{* *} \\
(0,0299)\end{array}$ \\
\hline Fund. completo e médio incompleto & $\begin{array}{l}-0,0638^{* * *} \\
(0,0179)\end{array}$ & $\begin{array}{l}-0,0627^{* * *} \\
(0,0114)\end{array}$ & $\begin{array}{l}-0,0630^{* * *} \\
(0,0096)\end{array}$ \\
\hline Médio comp. e superior incompleto & $\begin{array}{l}-0,1921^{* * *} \\
(0,0179)\end{array}$ & $\begin{array}{l}-0,1906^{* * *} \\
(0,0114)\end{array}$ & $\begin{array}{l}-0,1914^{* * *} \\
(0,0096)\end{array}$ \\
\hline Superior completo & $\begin{array}{l}-0,4609^{* * *} \\
(0,0330)\end{array}$ & $\begin{array}{l}-0,4539^{* * *} \\
(0,0226)\end{array}$ & $\begin{array}{l}-0,4569^{* * *} \\
(0,0186)\end{array}$ \\
\hline \multicolumn{4}{|l|}{ Composição da família } \\
\hline Número de irmãos (0 a 5 anos) & $\begin{array}{l}-0,0264 \\
(0,0207)\end{array}$ & $\begin{array}{l}-0,0211^{*} \\
(0,0123)\end{array}$ & $\begin{array}{l}-0,0229^{* *} \\
(0,0105)\end{array}$ \\
\hline Número de irmãs ( 0 a 5 anos) & $\begin{array}{l}0,0420^{* *} \\
(0,0199)\end{array}$ & $\begin{array}{l}0,0298^{* *} \\
(0,0124)\end{array}$ & $\begin{array}{l}0,0325^{\star * *} \\
(0,0105)\end{array}$ \\
\hline Número de irmãos (6 a 9 anos) & $\begin{array}{c}0,0210 \\
(0,0169)\end{array}$ & $\begin{array}{c}0,0087 \\
(0,0105)\end{array}$ & $\begin{array}{c}0,0107 \\
(0,0089)\end{array}$ \\
\hline Número de irmãs (6 a 9 anos) & $\begin{array}{l}0,0514^{* * *} \\
(0,0164)\end{array}$ & $\begin{array}{c}0,0138 \\
(0,0107)\end{array}$ & $\begin{array}{l}0,0227^{* *} \\
(0,0090)\end{array}$ \\
\hline Número de irmãos (15 a 17 anos) & $\begin{array}{r}0,0274^{*} \\
(0,0156)\end{array}$ & $\begin{array}{l}0,0671^{* * *} \\
(0,0099)\end{array}$ & $\begin{array}{l}0,0545^{* * *} \\
(0,0084)\end{array}$ \\
\hline Número de irmãs (15 a 17 anos) & $\begin{array}{l}0,0592^{* * *} \\
(0,0152)\end{array}$ & $\begin{array}{l}0,0354^{* * *} \\
(0,0106)\end{array}$ & $\begin{array}{l}0,0422^{* * *} \\
(0,0087)\end{array}$ \\
\hline \multicolumn{4}{|l|}{ Mercado de trabalho } \\
\hline Taxa de desemprego & $\begin{array}{l}-1,0804^{* * *} \\
(0,1575)\end{array}$ & $\begin{array}{l}-0,8411^{* * *} \\
(0,1065)\end{array}$ & $\begin{array}{l}-0,9111^{* * *} \\
(0,0885)\end{array}$ \\
\hline Taxa de informalidade & $\begin{array}{l}0,5579 * * * \\
(0,0659)\end{array}$ & $\begin{array}{l}0,6979^{* * *} \\
(0,0429)\end{array}$ & $\begin{array}{l}0,6510^{* * *} \\
(0,0359)\end{array}$ \\
\hline \multicolumn{4}{|l|}{ Localização } \\
\hline Metrópole & $\begin{array}{l}-0,0710^{* * *} \\
(0,0160)\end{array}$ & $\begin{array}{l}-0,0876^{* * *} \\
(0,0103)\end{array}$ & $\begin{array}{l}-0,0831^{* * *} \\
(0,0087)\end{array}$ \\
\hline Rondônia & $\begin{array}{l}0,2021^{* * *} \\
(0,0607)\end{array}$ & $\begin{array}{c}0,0984^{* *} \\
(0,0386)\end{array}$ & $\begin{array}{l}0,1283^{* * *} \\
(0,0325)\end{array}$ \\
\hline Acre & $\begin{array}{l}-0,0769 \\
(0,0869)\end{array}$ & $\begin{array}{l}-0,1621^{* *} \\
(0,0814)\end{array}$ & $\begin{array}{l}-0,1369^{* *} \\
(0,0605)\end{array}$ \\
\hline Amazonas & $\begin{array}{l}-0,1057 \\
(0,0665)\end{array}$ & $\begin{array}{l}-0,1688^{* * *} \\
(0,0423)\end{array}$ & $\begin{array}{l}-0,1460^{* * *} \\
(0,0357)\end{array}$ \\
\hline Roraima & $\begin{array}{l}-0,0442 \\
(0,1315)\end{array}$ & $\begin{array}{l}-0,1345 \\
(0,0907)\end{array}$ & $\begin{array}{l}-0,1086 \\
(0,0746)\end{array}$ \\
\hline Pará & $\begin{array}{l}-0,0622 \\
(0,0455)\end{array}$ & $\begin{array}{l}-0,1809^{* * *} \\
(0,0301)\end{array}$ & $\begin{array}{l}-0,1458^{* * *} \\
(0,0251)\end{array}$ \\
\hline Amapá & $\begin{array}{l}-0,1334 \\
(0,1004)\end{array}$ & $\begin{array}{l}-0,2489^{* * *} \\
(0,0810)\end{array}$ & $\begin{array}{l}-0,2118^{\star * *} \\
(0,0631)\end{array}$ \\
\hline
\end{tabular}


Tabela A.2 - Coeficientes estimados - regressões probit por tipo de família (continuação)

\begin{tabular}{|c|c|c|c|}
\hline & $\begin{array}{c}(1) \\
\text { Monoparental chefiada } \\
\text { pela mãe }\end{array}$ & $\begin{array}{c}(2) \\
\text { Biparental chefiada } \\
\text { pelo pai }\end{array}$ & $\begin{array}{c}(3) \\
\text { Ambas }\end{array}$ \\
\hline \multirow[t]{2}{*}{ Tocantins } & 0,0063 & $-0,0888^{* *}$ & $-0,0616^{*}$ \\
\hline & $(0,0574)$ & $(0,0388)$ & $(0,0321)$ \\
\hline \multirow[t]{2}{*}{ Maranhão } & $-0,0916^{*}$ & $-0,2591^{* * *}$ & $-0,2081^{* * *}$ \\
\hline & $(0,0468)$ & $(0,0326)$ & $(0,0267)$ \\
\hline \multirow[t]{2}{*}{ Piauí } & $-0,1477^{\star * *}$ & $-0,2571^{\star * *}$ & $-0,2238^{* * *}$ \\
\hline & $(0,0555)$ & $(0,0365)$ & $(0,0305)$ \\
\hline \multirow[t]{2}{*}{ Ceará } & $-0,0267$ & $-0,1935^{\star * *}$ & $-0,1399^{* * *}$ \\
\hline & $(0,0381)$ & $(0,0279)$ & $(0,0224)$ \\
\hline \multirow[t]{2}{*}{ Rio Grande do Norte } & $-0,1766^{\star * *}$ & $-0,2669^{* * *}$ & $-0,2391^{* * *}$ \\
\hline & $(0,0591)$ & $(0,0365)$ & $(0,0311)$ \\
\hline \multirow[t]{2}{*}{ Paraíba } & $-0,0717$ & $-0,1699^{* * *}$ & $-0,1395^{\star * *}$ \\
\hline & $(0,0492)$ & $(0,0313)$ & $(0,0264)$ \\
\hline \multirow[t]{2}{*}{ Pernambuco } & 0,0262 & $-0,1278^{* * *}$ & $-0,0784^{* * *}$ \\
\hline & $(0,0363)$ & $(0,0268)$ & $(0,0215)$ \\
\hline \multirow[t]{2}{*}{ Alagoas } & $-0,0466$ & $-0,1954^{* * *}$ & $-0,1486^{\star * *}$ \\
\hline & $(0,0570)$ & $(0,0400)$ & $(0,0327)$ \\
\hline \multirow[t]{2}{*}{ Sergipe } & $-0,1236^{*}$ & $-0,2166^{* * *}$ & $-0,1881^{\star * *}$ \\
\hline & $(0,0642)$ & $(0,0489)$ & $(0,0389)$ \\
\hline \multirow[t]{2}{*}{ Bahia } & 0,0400 & $-0,1345^{\star * *}$ & $-0,0776^{\star * *}$ \\
\hline & $(0,0331)$ & $(0,0240)$ & $(0,0193)$ \\
\hline \multirow[t]{2}{*}{ Minas Gerais } & $0,0951^{* * *}$ & $0,0299^{\star *}$ & $0,0481^{\star * *}$ \\
\hline & $(0,0237)$ & $(0,0149)$ & $(0,0126)$ \\
\hline \multirow[t]{2}{*}{ Espírito Santo } & 0,0666 & $-0,0397$ & $-0,0086$ \\
\hline & $(0,0479)$ & $(0,0322)$ & $(0,0267)$ \\
\hline \multirow[t]{2}{*}{ Rio de Janeiro } & $-0,1037^{* * *}$ & $-0,1861^{* * *}$ & $-0,1605^{\star * *}$ \\
\hline & $(0,0326)$ & $(0,0238)$ & $(0,0191)$ \\
\hline \multirow[t]{2}{*}{ Paraná } & $0,1753^{\star * *}$ & $0,1716^{\star * *}$ & $0,1739^{* * *}$ \\
\hline & $(0,0287)$ & $(0,0164)$ & $(0,0143)$ \\
\hline \multirow[t]{2}{*}{ Santa Catarina } & $0,1720^{* * *}$ & $0,2311^{* * *}$ & $0,2191^{* * *}$ \\
\hline & $(0,0364)$ & $(0,0202)$ & $(0,0177)$ \\
\hline \multirow[t]{2}{*}{ Rio Grande do Sul } & 0,0078 & $0,0585^{* * *}$ & $0,0448^{* * *}$ \\
\hline & $(0,0307)$ & $(0,0185)$ & $(0,0159)$ \\
\hline \multirow[t]{2}{*}{ Mato Grosso do Sul } & $0,0981^{*}$ & $0,0551^{\star}$ & $0,0663^{\star \star}$ \\
\hline & $(0,0524)$ & $(0,0333)$ & $(0,0281)$ \\
\hline \multirow[t]{2}{*}{ Mato Grosso } & $0,2465^{\star * *}$ & $0,1365^{\star * *}$ & $0,1666^{* * *}$ \\
\hline & $(0,0452)$ & $(0,0283)$ & $(0,0240)$ \\
\hline \multirow[t]{2}{*}{ Goiás } & $0,2986^{* * *}$ & $0,2379^{* * *}$ & $0,2553^{* * *}$ \\
\hline & $(0,0332)$ & $(0,0206)$ & $(0,0175)$ \\
\hline \multirow[t]{2}{*}{ Distrito Federal } & 0,0492 & $-0,2259^{* * *}$ & $-0,1115^{*}$ \\
\hline & $(0,0921)$ & $(0,0809)$ & $(0,0603)$ \\
\hline \multirow[t]{2}{*}{ Biparental (chefiada pelo pai) } & & & $-0,1325^{\star * *}$ \\
\hline & & & $(0,0077)$ \\
\hline \multirow[t]{2}{*}{ Intercepto } & $-5,8106^{\star * *}$ & $-5,6837^{\star * *}$ & $-5,6190^{* * *}$ \\
\hline & $(0,0813)$ & $(0,0511)$ & $(0,0431)$ \\
\hline Predições corretas & $97,1 \%$ & $97,8 \%$ & $97,6 \%$ \\
\hline Probabilidade de a criança trabalhar & 0,0292 & 0,0218 & 0,0236 \\
\hline Observações & 201.960 & 608.799 & 810.759 \\
\hline
\end{tabular}

Notas: Desvios-padrão robustos à heteroscedasticidade e ao agrupamento de crianças por domicílio entre parênteses. $(* \star *)$ Estatisticamente significante a 1\%. (**) Estatisticamente significante a 5\%. (*) Estatisticamente significante a $10 \%$. Fonte: Elaboração própria com base em microdados do Censo Demográfico de 2010. 